\title{
Web-based Language Production Experiments: Semantic Interference Assessment is Robust for Spoken and Typed Response Modalities
}

\author{
Kirsten Stark ${ }^{1,2,3^{*}}$, Cornelia van Scherpenberg ${ }^{3,4,5^{*}}$, Hellmuth Obrig ${ }^{3,4,5}$, Rasha Abdel \\ Rahman ${ }^{2,3}$ \\ 1 Charité - Universitätsmedizin Berlin, corporate member of Freie Universität Berlin, \\ Humboldt-Universität zu Berlin, and Berlin Institute of Health, Einstein Center for \\ Neurosciences Berlin, Germany \\ 2 Department of Neurocognitive Psychology, Humboldt-Universität zu Berlin, Germany \\ 3 Berlin School of Mind and Brain, Humboldt-Universität zu Berlin, Germany \\ 4 Department of Neurology, Max Planck Institute for Human Cognitive and Brain Sciences, \\ German \\ 5 Clinic for Cognitive Neurology, University Hospital and Faculty of Medicine Leipzig, \\ Germany \\ * Shared first authorship
}

Correspondence concerning this article should be addressed to Kirsten Stark, Unter den Linden 6, 10099 Berlin. Email: kirsten.stark@hu-berlin.de

\section{Unpublished Manuscript, November 2021}

Copyright note: Creative Commons licence CC BY. This preprint has not undergone peer review. The Version of Record of this article is published in Behavior Research Methods and is available online at https://doi.org/10.3758/s13428-021-01768-2

\begin{abstract}
For experimental research on language production, temporal precision and high quality of the recorded audio-files are mandatory. These requirements are a considerable challenge if language production is to be investigated online. However, online research has a huge potential regarding efficiency, ecological validity and diversity of study-populations in psycholinguistic and related research, also beyond the current situation. Here, we supply confirmatory evidence that language production can be investigated online and demonstrate that the written naming responses (using the keyboard) are a reliable and efficient alternative to typical overt spoken responses. To assess semantic interference effects in both modalities we performed two pre-registered experiments ( $n=30$ each) in online settings using the participants' web-browsers. A cumulative semantic interference (CSI) paradigm was employed that required naming several exemplars of semantic categories within a seemingly unrelated sequence of objects. Reaction time (RT) is expected to increase linearly for each additional exemplar of a category. In experiment 1, CSI effects in naming times described in lab-based studies were replicated. In experiment 2, the responses were typed on participants' computer keyboards and the first correct key press was used for RT analysis. This novel response assessment yielded a qualitatively similar, very robust CSI effect. Besides technical ease of application, collecting typewritten responses and automatic data pre-processing substantially reduce the work load for language production research. Results of both experiments open new perspectives for research on RT-effects in language experiments across a wide range of contexts. JavaScript- and R-based implementations for data collection and processing are available for download.
\end{abstract}

Keywords: Language production, online experiments, overt speaking, keystrokes, typewritten naming, cumulative semantic interference, picture naming 
Conducting experiments online has huge potential to advance behavioural research, beyond the challenges of the current pandemic situation. By running experiments through web browsers and online platforms, large numbers of participants can be recruited for cross-sectional, longitudinal or single-time-point studies at their homes (e.g., Palan \& Schitter, 2018). Moreover, access to diverse ethnicities, across countries, age groups and social status is facilitated (e.g., Gallant \& Libben, 2019; Peer et al., 2017). Larger and more diverse study populations can increase statistical power and ecological validity (Henrich et al., 2010; Speed et al., 2018). While other fields started to tap into the potential of online experiments more than two decades ago (e.g., Krantz \& Reips, 2017), language production experiments-especially when targeting reaction times-have rarely been implemented in web-based settings (but see e.g., Gilquin, 2010 for a non reaction time language production experiment). This is partially due to the sensitivity to small effects in the range of tens of milliseconds and concerns regarding technical reliability and data quality when measuring overt language production. Recent evidence, however, suggests that studying language production via online platforms is possible. Overt naming responses acquired online have been demonstrated to be precise enough to detect speech-onset reaction time effects in the critical range of $\sim 15-50$ milliseconds (Fairs \& Strijkers, 2021; Vogt et al., 2021). In a picture-naming paradigm, Fairs \& Strijkers (Fairs \& Strijkers, 2021) replicated lab-based effects of word frequency in an online experiment run on the platform FindingFive (FindingFive Team, 2019) with 100 participants. For the picture word interference (PWI) effect (Bürki et al., 2020; Lupker, 1979), which requires naming object pictures overlaid with semantically related or unrelated distractor words, Vogt et al. (Vogt et al., 2021) showed onlinefeasibility reproducing the lab-based findings. They implemented the experiment on two different platforms (SoSci Survey, Leiner, 2019 and jsPsych, de Leeuw, 2015) with different participant cohorts (each $n=$ 48). A comparison of overt naming and manual name classifications via key press responses revealed similar semantic interference effects for both response modalities, replicating lab-based effects (Abdel Rahman \& Aristei, 2010). The results are highly encouraging, but online assessment of overt spoken responses was also shown to require careful planning of the technical setup and a considerable offline processing effort. Specifically, the authors note caveats regarding the sample size needed for online studies, (technical) noise and effortful (pre-)processing of the data. Similar to lab-based experiments, offline processing of the experimental data, participants' audio recordings, requires some cumbersome classification of correctness and post-processing of the vocal onset times within the audio files. There are programs to assist such tasks (Boersma \& Weenink, 2020; Roux et al., 2017), but depending on the number of trials and participants it can still take several days to pre-process the files.

Typing instead of overtly pronouncing the word may be an alternative which could ease analyses and application. Indeed, studies have shown that typewritten responses can be a valid alternative modality of language production (Pinet \& Nozari, 2018; Torrance et al., 2018). This highlights the fact that the study of written language is coequal to spoken language in many linguistic questions. In an online format, this modality may have much fewer limitations as it can be implemented and processed more easily. Latencies of simple key presses (e.g. 'c' for correct) or mouse clicks are regularly used in both lab-based and online experiments. Since their implementation is rather undemanding, they have been implemented in a wide variety of online experiments, including psycholinguistic experiments using categorization tasks (Mathôt \& March, 2021; Vogt et al., 2021). Analysing a typed whole word response in language production is slightly more challenging, but it has been shown that typewritten responses can be pre-processed automatically and a wide range of different procedures exists, even controlling for typing errors (Borrie et al., 2019; Bosker, 2021; Navarro, 2001). Experiments with typewritten answers can thus be an easy-to-implement, time-efficient alternative to spoken responses in reaction- 
time sensitive language production experiments.

To further explore the potential of webbased experiments targeting language we here address three questions: (i) Can the well-documented cumulative semantic interference effect (CSI) be replicated in a web-based study design? (ii) How similar is the effect between two modalities, i.e. typed vs. microphone-recorded, spoken response? (iii) What recommendations can be provided regarding technical challenges of both approaches.

\section{(i) Can the Cumulative Semantic Interference (CSI) be Replicated Online?}

In experiment 1 , we set out to replicate labbased language production effects using the CSI paradigm in the same experimental platform and audio-recording method (SoSci Survey; Leiner, 2019; Khan 2020) as described in Vogt et al. (Vogt et al., 2021), Experiment 1. The CSI paradigm requires to name several exemplars of semantic categories within a seemingly unrelated sequence of objects. In lab-based experiments, reactions times increase linearly for each additional exemplar of a category being named. If this semantic interference effect replicates in an online setting we confirm the feasibility of timesensitive overt naming experiments in participants' web browsers.

(ii) Are Web-Based Recordings of the CSI-Effect Comparable for Spoken Versus Written (Typed) Response Modalities?

In experiment 2 of the current study, we ran the same language production paradigm on the same experimental platform but collected typed instead of spoken responses to the target pictures. Since spoken and written language production share underlying linguistic processes, the experiment targets the question whether typing may serve as a reliable alternative response modality in online experiments on language production which are targeting especially timing but also accuracy of the responses.

Of note, writing requires additional skills, acquired later in life. The degree of shared and unique processes in the two response modalities is still a matter of debate, but most theories assume that lexical processing stages are shared across different output modalities (Levelt et al., 1999; Logan \& Crump, 2011; Pickering \& Garrod, 2013; Roelofs, 2018). Keyboard typing - today undoubtedly the major way of peer-to-peer distant interaction (Brandt, 2015; Pinet et al., 2016a) - and handwriting diverge regarding certain aspects of motricity and motor planning (e.g., for complex writing systems Higashiyama et al., 2015), but research suggests that they share central linguistic mechanisms (e.g., Pinet et al., 2016b; see also Qu et al., 2020). With regard to written versus spoken responses it has been shown that both are modulated by lexical frequency, age of acquisition, and image agreement (Bertram et al., 2015; Bonin et al., 2002; Pinet et al., 2016b; Torrance et al., 2018). Moreover, phonological priming effects are similar in both modalities (Breining et al., 2016; Chen \& Li, 2011; Qu \& Damian, 2020; Roux \& Bonin, 2012; Zhang \& Damian, 2010). For picture naming, written naming was mostly found to be slower compared to spoken naming (Bonin \& Fayol, 2000; Chen \& Li, 2011). Interestingly, differences tend to disappear when participants see what they write (Perret \& Laganaro, 2013; Snyder et al., 2015). Extending the modality comparison to web-based assessment may be of special interest in future studies targeting cohorts with special requirements since they may profit from assessing the effect in one rather than the other modality (e.g. people with aphasia, people with dysarthria).

\section{(iii) What are the Technical Challenges and how Can we Address Them?}

Regardless of response modality, technical demands of online experiments involve specific computational and hardware/software-related characteristics (see e.g. Grootswagers, 2020 for an overview of the general infrastructure of online experiments). One computational aspect is the integration of recording of the audio input and the typing latencies themselves. Recent JavaScript-based implementations make this possible. JavaScript is a programming language native to all modern browsers and thereby does not need installation prior to testing, neither on the programmers' nor on the 
users' side. In combination with HTML and CSS, it forms the core technology of the world wide web. It is event-driven, that is, it allows for programming reactions to any "event" with high temporal precision and without reloading the web page. Events can, for instance, be keypresses or mouse clicks. JavaScript can also time the presentation of elements, such as pictures and texts, defined and styled with HTML and CSS. JavaScript-based implementations can be combined with most platforms for online surveys and experiments which allow the experimenter to enter JavaScript code chunks. For the current study, audio recordings were acquired using a JavaScript plugin available on GitHub (Khan, 2020). For detecting key stroke latencies, we programmed a custom JavaScript (Stark, 2021b) which we make available for download.

Regarding hardware and software demands, a major aspect is the variability between participants. A precise time lock between stimulus presentation and onset of the recording or timer is crucial. In the lab, the technical properties can be controlled, and are mostly stable across participants. In online experiments, the hardware and software varies between participants and can corrupt data quality and signal-to-noise ratio (Anwyl-Irvine et al., 2020a; Bridges et al., 2020). Sources of variance are the experimental platform and browser used, the operating system, and the type and quality of participants' microphones and their interface to the further hardware. For instance, one study found that the interface between audio system and operating computer (analog-to-digital and digital-toanalog conversion) introduced uncontrolled latency jittering of about 5-10 ms (Kim et al., 2020). However, when put into practice, the overall noise seems to affect data quality less than expected. Being relatively stable for a single participant, we can assume relatively high precision for within-subject comparisons with a sufficient amount of trials (Bridges et al., 2020; Pinet et al., 2017; Vogt et al., 2021; see Baker et al., 2020 for a recent article on how sample size and number of trials affect statistical power). Regarding keypresses, a previous study compared the objective timing of different devices (Reimers \& Stewart, 2015). Absolute overestimation of RTs ranged from
30 to $100 \mathrm{~ms}$ on different hardware/software systems and web browsers. The variability within a single system, however, was comparatively low (<10 ms). Hence, the authors conclude that "within-subject comparison of response times across two conditions is almost unaffected" in webbased research. Although estimations of the actual noise introduced by a single participants' system are extremely difficult regarding both within and between participant data, the reported results are encouraging (see also more recent studies by Anwyl-Irvine et al., 2020; Bridges et al., 2020). We thus proceed from the assumption that the additional noise does not affect the interpretation of within-subject comparisons if the effects are well above 10 $\mathrm{ms}$ and if no randomization between participants is necessary.

In summary, the two experiments presented here aim at (i) providing confirmatory evidence that web-based language production experiments yield reliable withinsubject effects if a sufficient number of trials is employed (experiment 1). Furthermore, we investigated (ii) whether reaction time (and, exploratory, error rate) effects are comparable for typewritten and spoken response modalities (experiment 2). Addressing the issue of pre-processing after data-collection we compared manual and automatic classification procedures of typewritten answers. This aims at (iii) improving the workflow and technical ease of application. To encourage broader use of web-based language production research, we provide materials and guidelines that may help researchers to plan their own reaction time experiments online.

Both experiments (experiment 1: spoken responses and experiment 2: typed responses) were programmed and run on the platform SoSci Survey (Leiner, 2019), a Germany-based platform for conducting social and behavioural research. For experiment 1, audio recording was implemented using the JavaScript-based plugin RecordRTC (Khan, 2020). For experiment 2 , the keystroke onsets were detected using customized JavaScript (Stark, 2021b). Materials, design, and procedure of the two experiments were largely identical and are described in detail below and visualized in Figure 1. Both experiments and the analyses were 
preregistered on the open science

framework (experiment 1: t1p.de/hy8q,

experiment 2: $\underline{\text { t1p.de/866o }}$ ).

\section{Figure 1}

Overview of the Experimental Procedures in Experiments 1 and 2

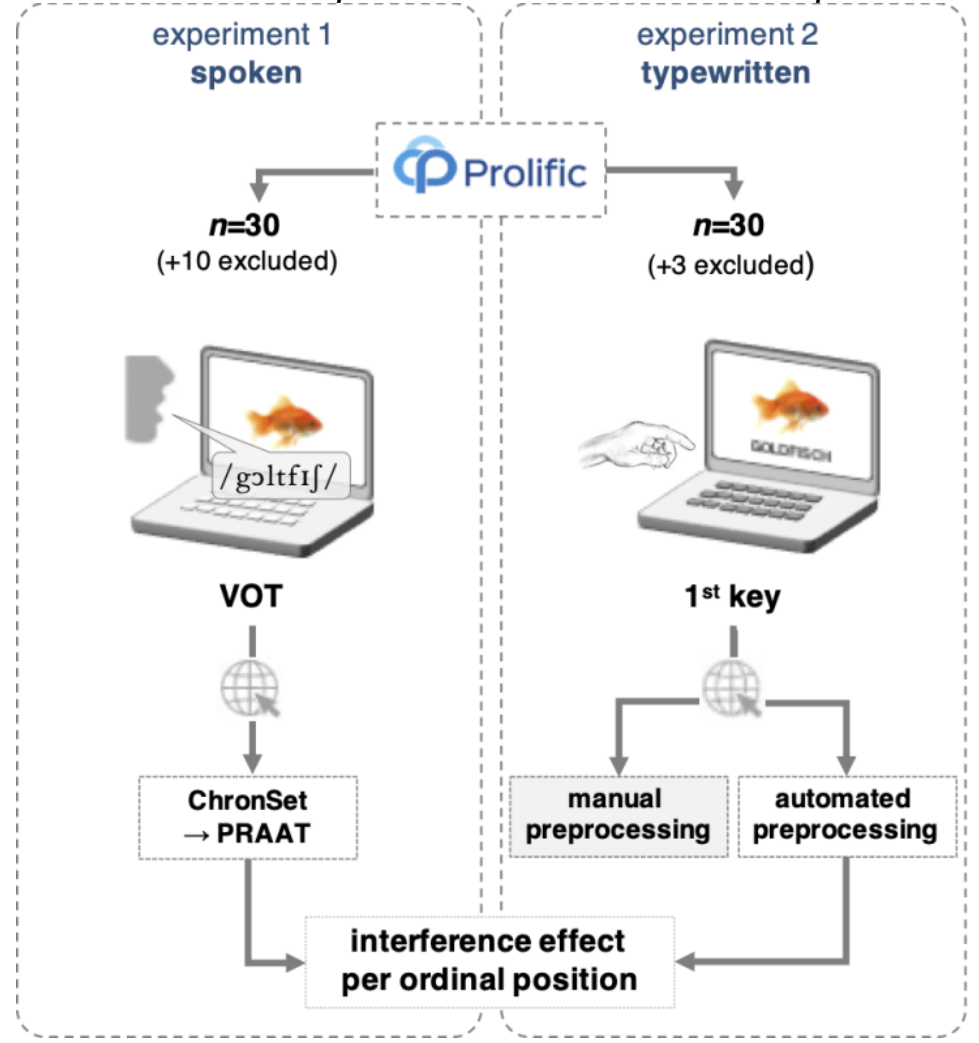

\section{Experiment 1: CSI With Spoken Responses}

\section{Methods}

\section{Participants}

40 native German speakers between 18 and 35 years were recruited via the commercial platform Prolific (www.prolific.co.uk) and completed the full experiment. Following the preregistered criteria, the final sample comprised only participants who reached a minimum of $80 \%$ of valid or correct trials and passed the criteria to ensure sufficient attention during online performance. Accordingly, we excluded one participant who had failed the second attention check (item vs. non item), one due to missing audio recordings, and eight due to too many null responses or other errors resulting in trial loss $>80 \%$. To determine the necessary final sample size, we ran an a-priori power analysis using the R package simr (Green \& MacLeod, 2016), based on estimates from a previous, lab-based continuous naming study (Rose \& Abdel Rahman, 2016). This resulted in a suggested sample size of 24 for a power estimate of $80 \%$. To account for expected noise in the data sample due to the online setting, we a priori decided to increase the estimated sample size by 25 $\%$. The final sample thus consisted of 30 participants (16 females, aged 19-35, Mage $=$ $\left.26.5, S D_{\text {age }}=5.1\right)$.

Experimental procedures were approved by the Institutional Review Board of the University of Leipzig, Germany, in accordance with the Declaration of Helsinki (amendment to ethical approval AZ 144/18ek, Ethics Committee University Leipzig). All participants gave their informed consent at the beginning of the study and were rewarded monetarily. 


\section{Material}

The 160 experimental stimuli used in the study were coloured photographs of everyday objects. The 120 target stimuli consisted of 24 semantic subcategories with 5 closely related members each. For example, /shark/, /eel/, /ray/, /goldfish/ and /dolphin/ constituted the subcategory fish as part of the superordinate category animals. Other categories were, e.g., fruit (food), seating furniture (furniture); for a full list see Appendix A. Additionally, 40 fillers were added to the overall item set (25\%).

\section{Design}

The 24 categories were distributed across 8 blocks of 3 categories each. To each block, 5 filler items were added, resulting in 8 blocks à 20 items. 5 block orders were created in a pseudorandomised fashion such that categories that shared a superordinate semantic category (e.g., fish and insects: animals), were as far apart as possible. Trial randomization was done using the program MIX (Van Casteren \& Davis, 2006). 6 randomised trial lists were created for each block order, resulting in a total of 30 randomised lists. When participants opened the survey in Prolific but did not complete the experiment, they were assigned a randomized list but were not listed amongst the 40 paid participants. Due to the random assignment of the lists by SoSci Survey, few lists were hence used several times whereas others were not used at all. Trial randomisation was constrained in that within each block, members of each category were separated by at least 2 (lag = 2) and maximum 8 items (lag $=8$ ), including fillers and members of different categories. Note that previous research suggests that lag, i.e. the distance between two ordinal positions within one semantic subcategory, does not affect the cumulative semantic interference effect across ordinal positions (e.g. Schnur, 2014).

\section{Procedure}

The experiment started with an instruction of the general procedure to which the participants consented. They were then familiarized with the materials, by presenting eight pictures each on the screen with their names written underneath. The participants were instructed to look at the pictures closely, read their names (if possible, aloud), and to proceed to the next set of pictures, self-paced by pressing the space bar or enter key. After familiarization, a catch trial showed two previously seen and two novel items, to check whether participants had paid attention to the pictures. Response was mandatory but was only used for later assessment of data quality, and participants were able to proceed regardless of their answer. This was followed by instructions to allow the browser to access the computer microphone. After that, participants were instructed to name each presented picture as quickly and accurately as possible. Following four practice trials, the main task started. After a fixation cross, presented for $500 \mathrm{~ms}$, the target picture appeared for $2 \mathrm{~s}$. The audio-recording was started with the appearance of the picture and lasted for 2.5 $\mathrm{s}$. The next trial started automatically. After completion of the 160 trials, the experiment finished with another attention check (two previously named and two novel items), a debriefing page and the option to leave comments. The whole experiment lasted around 15 minutes on average (range $=10$ -20 minutes).

\section{Data Processing}

The recorded audio files were retrieved from the SoSci Survey server and converted into wav files. Vocal onset times (VOTs) were detected using the Chronset algorithm (Roux et al., 2017), and checked manually using a customized Praat script (Boersma \& Weenink, 2020; van Scherpenberg et al., 2020). The final VOTs were determined at the start of each word, excluding stuttering or "uhms". These VOTs were considered the overt response, i.e., the reaction times. From the overall 4800 observations (160 trials *30 participants), 100 were excluded due to missing responses or technical errors. 269 trials were excluded due to incorrect naming. These included semantic errors (e.g., "car" for "carriage", $n=187$ ), naming of unrelated words (e.g., mushroom for ball, $n=31$ ) or other errors such as naming of articles before the word or stuttering $(n=51)$. On average, $7.69 \%$ of participants' responses were considered as incorrect ( $S D=3.85 \%)$.

Statistical analyses were thus based on 3264 observations (4800 observations 
excluding the 1200 filler trials (40 trials * 30 participants) and 369 erroneous trials).

\section{Statistical Analyses}

Statistical analyses for both experiments were done in $\mathrm{R}$ (version 4.0.2; $\mathrm{R}$ Core Team, 2020). Following the procedure suggested by Lo \& Andrews (Lo \& Andrews, 2015), to account for the non-normal, skewed distribution of the raw reaction time data, generalized linear mixed models (GLMM) were run with a Gamma distribution and identity link function, using the $R$ package Ime4 (version 1.1-23; Bates et al., 2014). $P$-values were calculated using the Wald Z-statistics. Reaction times (RTs) were entered as the dependent variable and ordinal position as a continuous, meancentred predictor. The model converged with the fully specified crossed random effects structure (Barr et al., 2013) including intercepts and slopes of the ordinal position for both subjects and categories. For the exploratory analyses of error rates, a generalized linear mixed model with a Binomial distribution was computed. Initially, the model was specified with the same fullycrossed random effects structure as for the RT-analyses. Due to converge problems, we then adopted our preregistered model reduction procedure, following the recommendations by Brauer and Curtin (2018) by increasing the number of optimizer iterations to $2 \cdot 10^{5}$, and subsequently, reducing the random structure. The model converged with a random intercept for subjects and a random intercept and slope for categories. Anonymized data and scripts are provided on the Open Science Framework: https://osf.io/w6ptm/.

\section{Results}

The mean RTs across ordinal positions are visualized in Figure 2. As can be seen, they follow a linear increase with a plateau at ordinal position 4. To confirm this linear trend statistically, we ran a GLMM as described above, with a fully specified random structure. The results are summarized in Table 1. This confirmed that RTs increased significantly with an average of $\sim 31 \mathrm{~ms}$ per ordinal position. As shown in Table 2, error rates also increased with ordinal position. Averages for each participant and each category (RTs and error rates) are provided in Appendix B.

\section{Figure 2}

Mean Naming Latencies (RTs) in Milliseconds as a Function of Ordinal Position

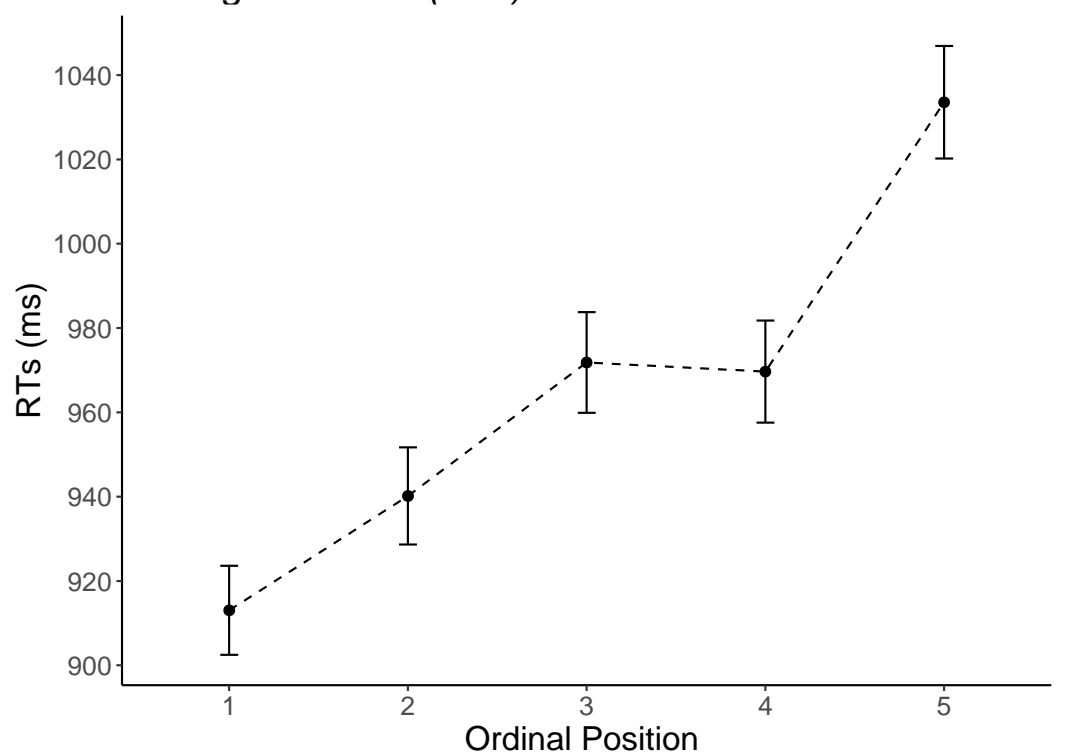

Note. Mean reaction times (RTs) were calculated across semantic categories and participants. Error bars show standard errors of the mean. Values were adjusted for within-participant designs using the method suggested by Morey (Morey, 2008) as implemented in the summarySEwithin( ) function from the $R$ package Rmisc (Hope, 2013). 


\section{Experiment 2: CSI With Typewritten Picture Naming}

\section{Methods}

\section{Participants}

For experiment 2, another group of 33 native German speakers aged between 18 and 35 years was recruited via Prolific (www.prolific.co.uk), none of whom had participated in the first experiment. All participants entered the experiment using a computer or laptop and a QWERTZkeyboard, the most widely-used keyboard type in Germany. Based on our preregistered inclusion criteria, which were identical to experiment 1 (a minimum of 80 $\%$ of valid trials in the CSI task and correct answers in the attention checks), 3 participants were excluded ${ }^{1}$. Thus, the final sample consisted of 30 participants (9 female; 4 left-handed; aged 18-35, $M_{\text {age }}=$ $\left.25.4, S D_{\text {age }}=4.6\right)$. Their mean typing speed was 15.3 five characters-words per minute $(S D=7.5$; range 4.0 to 34.1$)$ and their accuracy was $80 \%(S D=9.5$; range 64 to 94 ), as assessed by a typing test (see below).

Sample size was determined to be identical to experiment 1, and an a-priori power analysis (simr, version 1.0.5; Green \& MacLeod, 2016) based on the fixed and random estimates from experiment 1 suggested a power $>85 \%$ to detect an effect of similar magnitude with 30 participants. Experimental procedures were approved by the local ethics board of the HumboldtUniversität zu Berlin, in accordance with the Declaration of Helsinki (ethical approval 2020-68). All participants gave their informed consent and were rewarded monetarily.

\section{Material, Design, and Procedure}

The 160 experimental stimuli were identical to experiment 1 , and design and procedure of both experiments were kept largely identical. The different response modality resulted in 4 modifications of the design of experiment 1: (1) Upon opening the study link, participants were screened for using a QWERTZ-keyboard (i.e., the six first letters of the upper letter row being $Q, W, E, R, T$,

\footnotetext{
1 One of these participants was excluded based on her comment that she was living abroad and was no
}

and Z) using a custom JavaScript plugin (based on the comparison of the event.key( ) and event.code( ) methods, available at https://github.com/kirstenstark/typing RTs $\underline{\mathrm{JS}})$. This was done to ensure that all participants had direct keys for all German letters (e.g., 'ö' and ' $\beta$ ') and key positions were identical between participants. (2) During the familiarization with the material, pictures and picture names were presented one after another at a central position on the screen. For each picture, the participants were instructed to type the picture name at their own pace in a text box displayed underneath the picture. Participants saw what they typed and were allowed to correct answers using the backspace button. To keep the familiarization comparable to experiment 1, no feedback on the correctness of the typed answer was given. Prior to the familiarization, participants had been instructed to enable the caps lock key and to write all letters in upper case. Regardless of whether they adhered to the instructions, the typed characters were always displayed in capital letters. Because German nouns start with a capital letter, this was done to accustom participants to not press the shift key upon the beginning of each typed word. (3) During the main experimental task, participants were instructed to type the name of each presented picture as quickly and accurately as possible. They were informed that single spelling mistakes ("typos") were not a problem. In each trial, a fixation crossidentical to experiment 1-was presented for $500 \mathrm{~ms}$ after the page was fully loaded. The following target picture was displayed for 6 $\mathrm{s}$ (as opposed to $2 \mathrm{~s}$ in experiment 1 ) or until the space bar or enter key was pressed. Like during familiarization, the typed answers appeared in a text box below the target picture, and corrections using the backspace key were allowed. (4) At the end of the experiment, to achieve an accurate sample description, participants performed a typing test in which they copied three texts of $\sim 155$ characters each in their usual typing speed. Participants' typing accuracy and speed were calculated by taking the percentage of 5 character-words containing no errors or backspaces and by dividing the

longer used to typing in German. The other two were excluded due to trial loss $>80 \%$. 
number of correct 5 character-words by the total time needed for all 5 character-words (see Crump \& Logan, 2010; Pinet et al., 2016a). The whole experiment lasted around 28 minutes on average (range $=19$ -55 minutes).

Although the experimental platform SoSci Survey is mainly PHP-based, HTML, CSS, and JavaScript code can be implemented to customize a survey. Thus, keystrokes, keystroke latencies, and typed words were collected in the main experimental task using a custom script that relied on the JavaScript document.addEventListener( ) and keydown( ) methods, and the general JavaScript object Date( ). The JavaScript code and an implementation for SoSci Survey is available on GitHub (Stark, 2021b).

\section{Data Processing}

\section{Manual Pre-Processing}

The correctness of collected word entries was classified half-automatically based on our preregistered trial exclusion criteria, using custom scripts in $\mathrm{R}$ and Excel. Word entries were considered as correct if the expected picture name or an accepted synonym (see Appendix A) was entered. As reaction time analyses relied on the latency of the first keystroke only, word entries were also considered correct when the first character was correct and the typed word was recognizable for the coding experimenter despite typing errors. For each valid trial, the latency of the first keystroke was considered as the beginning of the overt response, i.e., the reaction time. Automated Pre-Processing

In comparison to the time-consuming preprocessing of spoken naming responses, the pre-processing of typed responses is less effortful because reaction times can be determined online. However, manually classifying the correctness of typed word entries still takes a considerable amount of time (Borrie et al., 2019). Automated assessment of typed responses can be a highly efficient and replicable method (within and between raters) to further reduce the

\footnotetext{
2 To date, there are several distance metrics available, each with specific characteristics and applications. We chose to base our analysis on the Jaro distance because this metric was tailored specifically to short string inputs. A comparison between different string matching metrices, including
}

effort (Bosker, 2021). To test the applicability of automated assessment in typed picture naming, we compared our semi-automatic/manual classification to an automated classification procedure using the Jaro distance. The Jaro distance (Jaro, $1989,1995)$ is a heuristic metric that compares character strings based on the number of and distance between matching characters, assuming that mismatches and transpositions between close characters are more likely to represent typing mistakes than mismatches between distant characters. It is implemented in the stringdist(method = "jw", $p=0$ ) function of the stringdist package in $\mathrm{R}$ (version 0.9.6.3; van der Loo, 2014). The metric is bounded between 0 and 1 ( 0 representing identical strings and 1 representing complete dissimilarity) and tailored specifically to human-typed, rather short strings (Bosker, 2021; van der Loo, 2014). ${ }^{2}$ For the exact formula applied, we may refer to van der Loo (van der Loo, 2014).

During the automated pre-processing, we (1) deleted space or enter keys at the end of a word string, (2) computed backspacecorrected word entries, e.g., by replacing "CHEBackspaceAIR" with "CHAIR", and (3) calculated the Jaro distance $d_{\text {Jaro }}$ between each backspace-corrected word entry and the picture name or accepted naming alternatives. The list of accepted naming alternatives was generated before and during the manual classification of spoken (experiment 1) and typed responses (experiment 2). A "best match" alternative naming was favoured over the actual picture name when the first character of the typed word entry and the alternative were identical and their Jaro distance was lower than the distance between word entry and picture name. (4) Finally, word entries were classified for correctness and different error types. A word entry was classified as correct if the first letter was typed correctly (i.e., item or "best match" alternative and word entry started with the same character, before and after backspace correction) and the Jaro distance was $d_{\text {Jaro }}<.3$. A word entry was

the Jaro-Winkler distance, the Levenshtein distance, the restricted Damerau-Levenshtein distance, and the Jaccard bi-gram distance, is reported in Appendix C. 
classified as incorrect if the first typed key was a special character, such as shift, space, or backspace, or an incorrect character, or if the Jaro distance was $d_{\text {Jaro }} \geq$ .3. All steps described above were implemented in separate $R$ functions which can be found on GitHub (Stark, 2021a; https://github.com/kirstenstark/stringmatch_ typed_naming).

\section{Statistical Analyses}

\section{Manual vs Automated Pre-Processing}

We compared the manual/half-automatic and automated classification procedures and found that, across participants, only $0.60 \%$ of all trials were classified differently: Of the 4800 trials, 8 trials manually classified as incorrect were classified as correct in the automated procedure ("new correct trials"), and 21 trials manually classified as correct were now considered as incorrect ("new incorrect trials"). The classification differences mainly occurred for the following reasons: (1) Participants backspace-corrected an accepted alternative, changing the first character of the word entry ( $n=13$ new incorrect words; e.g.,

BURBackspaceBackspaceBackspaceBack spaceSCHLOSS [BUR(G) vs. SCHLOSS; engl. castl(e)...fortress]), (2) they misspelled the beginning of a word with a phonologically similar phoneme $(n=6$ new incorrect words; e.g., PFEILE instead of FEILE [engl. similar to wrasp instead of rasp]), (3) they typed orthographically similar words ( $n=2$ new correct words; e.g., KESSEL [engl. kettle] instead of KELLE [engl. ladle]) or (4) they typed only parts of the picture name ( $n=5$ new correct words; e.g., GESCHIRR [engl. dish] instead of GESCHIRRSPÜLER [engl. dishwasher]). These unwarranted misclassifications can be considered negligible since the correlation between manual/semi-automatic and automated classification was close to perfect (Pearson's $r=.97$ ). The formulabased automated classification matched the intuitive manual classification almost completely. Therefore, we hereafter report the results based on the automated classification procedure. For comparison, we report the RT results based on the manual classification in the Appendix D, which are largely identical.

\section{Typing Errors}

On average, $10.85 \%(S D=4.73 \%)$ of word entries per participant were classified as incorrect. The different error types are summarized in Table 3 . The final statistical analyses of reaction times were thus based on 3178 observations (4800 observations excluding the 1200 filler and 521 erroneous trials [99 erroneous trials were fillers]), while the exploratory analyses of error rates were based on all 3600 observations.

To analyse participants' errors of typed responses, a generalized linear mixed model (GLMM) with a Binomial distribution was fitted to predict the error rates by ordinal position. The model converged after increasing the number of iterations to $2 \cdot 10^{5}$ and restricting the correlation parameters to zero. $P$-values were calculated using the Wald Z-statistics.

\section{Table 3}

Automated Classification of Typed Word Entries

\begin{tabular}{|c|c|c|c|c|c|c|c|}
\hline \multirow[t]{4}{*}{ Correct } & \multirow[t]{2}{*}{ Total } & \multicolumn{3}{|c|}{ Based on picture name } & \multicolumn{3}{|c|}{ Based on alternative naming } \\
\hline & & Identical & Corrected & $d_{\text {Jaro }}<.3$ & Identical & Corrected & $d_{\text {Jaro }}<.3$ \\
\hline & 4279 & 3519 & 301 & 133 & - & 302 & 24 \\
\hline & $(89 \%)$ & $(82.24 \%)$ & $(7.03 \%)$ & $(3.11 \%)$ & & $(7.06 \%)$ & $(0.56 \%)$ \\
\hline \multirow[t]{3}{*}{ Incorrect } & Total & $\overline{N A}$ & $\begin{array}{c}\text { Special } \\
\text { key start }\end{array}$ & $\begin{array}{l}\text { Shift } \\
\text { start }\end{array}$ & $d_{\text {Jaro }} \geq .3$ & $\begin{array}{c}1^{\text {st }} \text { letter } \\
\text { error }\end{array}$ & $\begin{array}{c}\text { Combine } \\
d\end{array}$ \\
\hline & 521 & 153 & 25 & 10 & 12 & 231 & 90 \\
\hline & $(11 \%)$ & $(29.37 \%)$ & $(4.80 \%)$ & $(1.92 \%)$ & $(2.30 \%)$ & $(44.34 \%)$ & $(17.27 \%)$ \\
\hline
\end{tabular}

Note. Identical $=$ participants typed the exact (alternative) picture name; Corrected $=$ participants backspace-corrected their word entry to the exact (alternative) picture name; $d_{\mathrm{Jar}}<.3=$ the Jaro 
distance between participants' backspace-corrected word entries and (alternative) picture name was below .3; $N A=$ No keystroke was detected (no answer given or technical error); Special key start = participants started by pressing the space, backspace, caps lock, or enter key; Shift start = participants started by pressing the shift key (which would be correct for German nouns if participants hadn't been instructed to enable the caps lock key and write everything in upper case); $d_{\text {Jaro }} \geq .3=$ the Jaro distance between participants' backspace corrected word entries and (alternative) picture names was greater or equal .3; $1^{\text {st }}$ letter error $=$ the first typed characters of word or backspace-corrected word were different from the first letter of the (alternative) picture name; combined = the Jaro distance exceeded the threshold for correctness $\left(d_{\mathrm{Jaro}} \geq .3\right)$ and the first typed letter was incorrect ( $1^{\text {st }}$ letter error).

\section{Reaction Time Analyses}

As for experiment 1, the distribution of the raw reaction times was skewed. Therefore, a GLMM with a Gamma distribution and identity link function was fitted to predict reaction times (RTs) by continuous, mean-centred ordinal position. $P$-values were calculated using the Wald $Z$ statistics. The model converged with the fully specified crossed random structure (Barr et al., 2013) including intercepts and slopes of the ordinal position for both subjects and categories. Anonymized data and scripts can be found on the open science framework: https://osf.io/gmnc8/.

\section{Results}

The mean reaction times, i.e., the latencies between picture onset and first keystroke (visualized in Figure 3) show a linear increase with ordinal position. The GLMM confirmed this linear trend: RTs increased significantly with an average of $\sim 42 \mathrm{~ms}$ per additional member of each category (Table 4). The error rates did not differ statistically between ordinal positions (Table 5). See Appendix B for a visualization of the CSI effect and of the error rates for each participant and category separately.

\section{Figure 3}

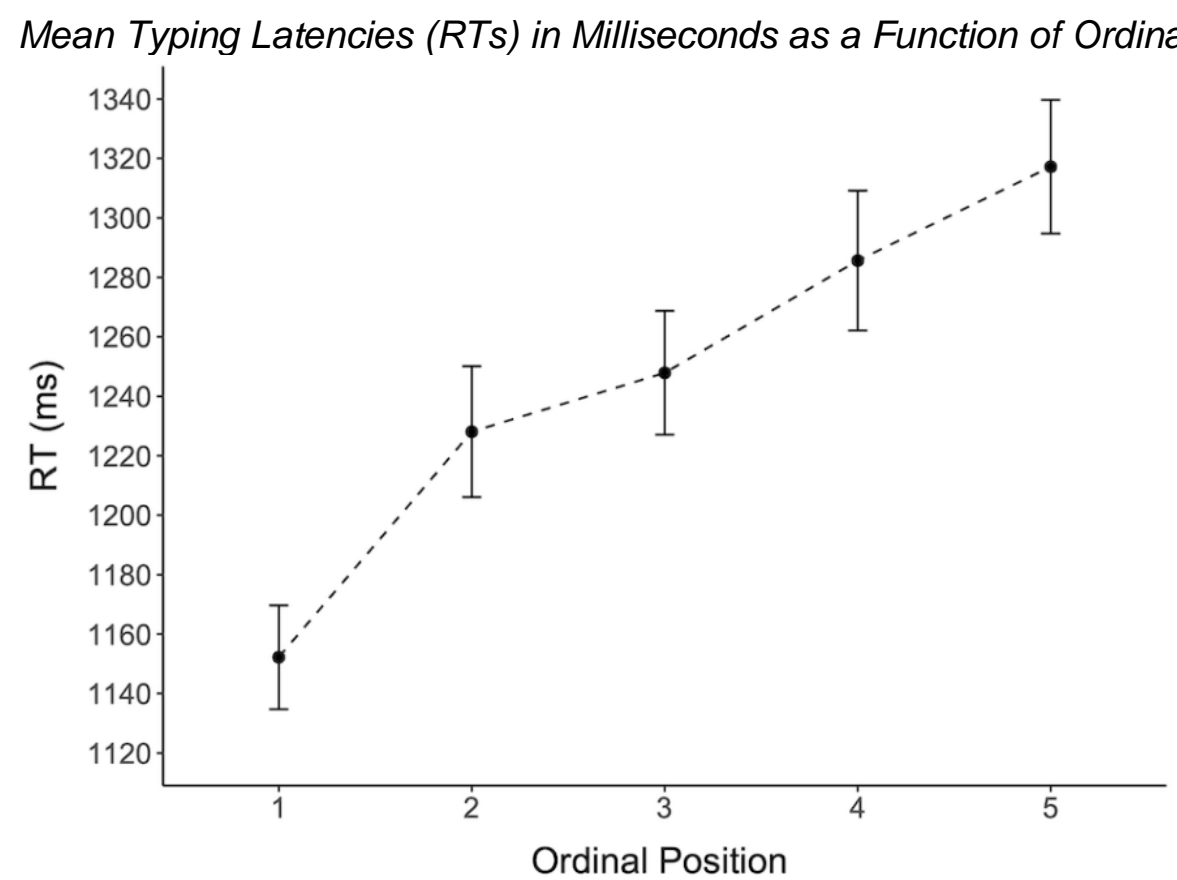

Note. Mean reaction times (first keystrokes) in milliseconds per ordinal position. Mean reaction times were calculated across semantic categories and participants. Error bars show standard errors of the mean. Values were adjusted for within-participant designs using the method suggested by Morey (Morey, 2008) as implemented in the summarySEwithin() function from the R package Rmisc (Hope, 2013). 
Table 4

Generalized Linear Mixed Model (GLMM) With Gamma Identity Link Function Predicting Typing Latencies (RTs) by Ordinal Position

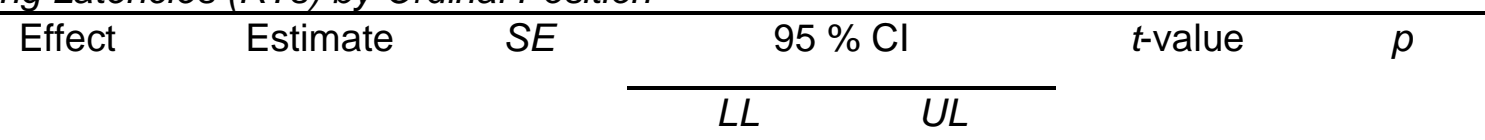

Model: RT ordinal position + (ordinal position | subject) + (ordinal position | category)

Fixed effects

$\begin{array}{lcccccc}\text { Intercept } & 1298.49 & 11.43 & 1276.08 & 1320.90 & 113.56 & <.001 \\ \text { Ordinal } & 41.68 & 6.83 & 28.29 & 55.06 & 6.10 & <.001 \\ \text { position } & & & & & & \end{array}$

position

Note. Number of participants $=30$; number of categories $=24 ;$ total $N=3178 ; S E=$ standard error; $\mathrm{Cl}=$ confidence interval around the estimate; $L L=$ lower limit; $U L=$ upper limit. $P$ values are based on a Wald $Z$-test. The model structure was identical to experiment 1 (see Table 1).

\section{Table 5}

GLMM With Binomial Distribution Predicting Error Rates by Ordinal Position

Effect Log-Odds SE $\frac{25 \% \mathrm{Cl}}{L L \quad U L}$-value $p$

Model: Errors ordinal position + (ordinal position || subject) + (ordinal position || category)

Fixed effects

\begin{tabular}{lcccccc} 
Intercept & -2.25 & 0.16 & -2.57 & -1.93 & -13.89 & $<.001$ \\
Ordinal Position & 0.05 & 0.05 & -0.04 & 0.15 & 1.06 & .291 \\
\hline
\end{tabular}

Percentage of erroneous trials
Ordinal position

$\begin{array}{cccccc} & 1 & 2 & 3 & 4 & 5 \\ M & 10.42 & 12.08 & 11.39 & 11.53 & 13.19 \\ \text { SEM } & 1.34 & 1.17 & 1.35 & 1.26 & 1.77\end{array}$

Note. Number of participants $=30 ;$ number of categories $=24$; total $N=3600 ; S E=$ standard error; $\mathrm{Cl}=$ confidence interval around the estimate; $L L=$ lower limit; $U L=$ upper limit; $M=$ mean; SEM = standard error of the mean (Morey, 2008); erroneous trials = Number of trials per ordinal position that were excluded due to errors (technical or answer-based). $P$ values are based on a Wald Z-test. 
Figure 4 shows a comparison of the linear trend and error rates found in our webbased experiments with those from a collection of several lab-based experiments using the same paradigm (see Table 6 for a detailed comparison of the collection of studies). As can be seen, the magnitude of the CSI effect (RT increase per ordinal position) in our web-based experiments with spoken responses fits well into that range, whereas the typed responses yield a numerically larger CSI effect. Error rates from both experiments fit well into the range reported in the lab-based experiments.

\section{Figure 4}

(A) Mean Naming Latencies (RTs) in Milliseconds (Normalized to the First Ordinal Position) and (B) Mean Error Rates as a Function of Ordinal Position Across Several Experiments Using the CSI Paradigm

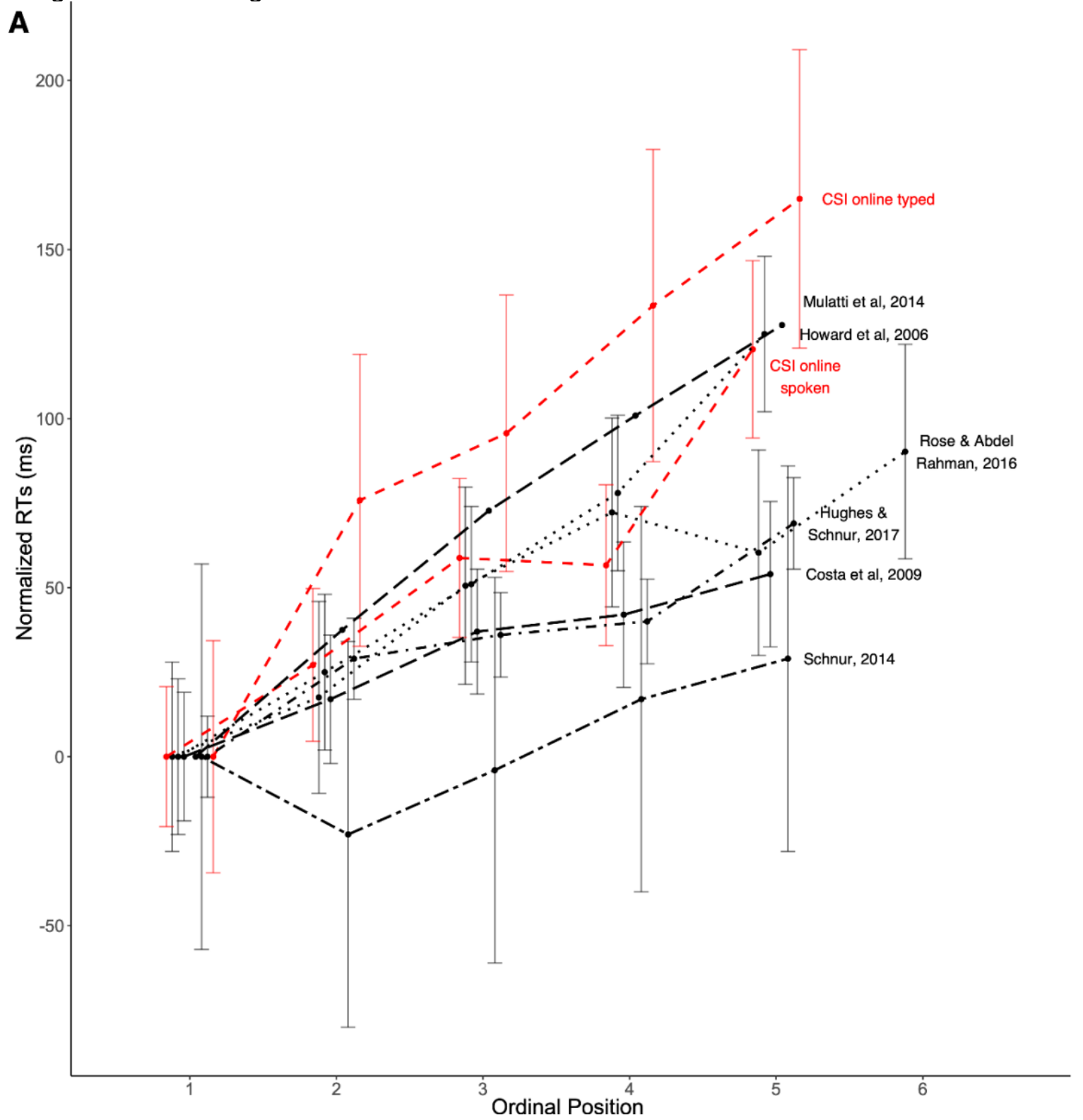




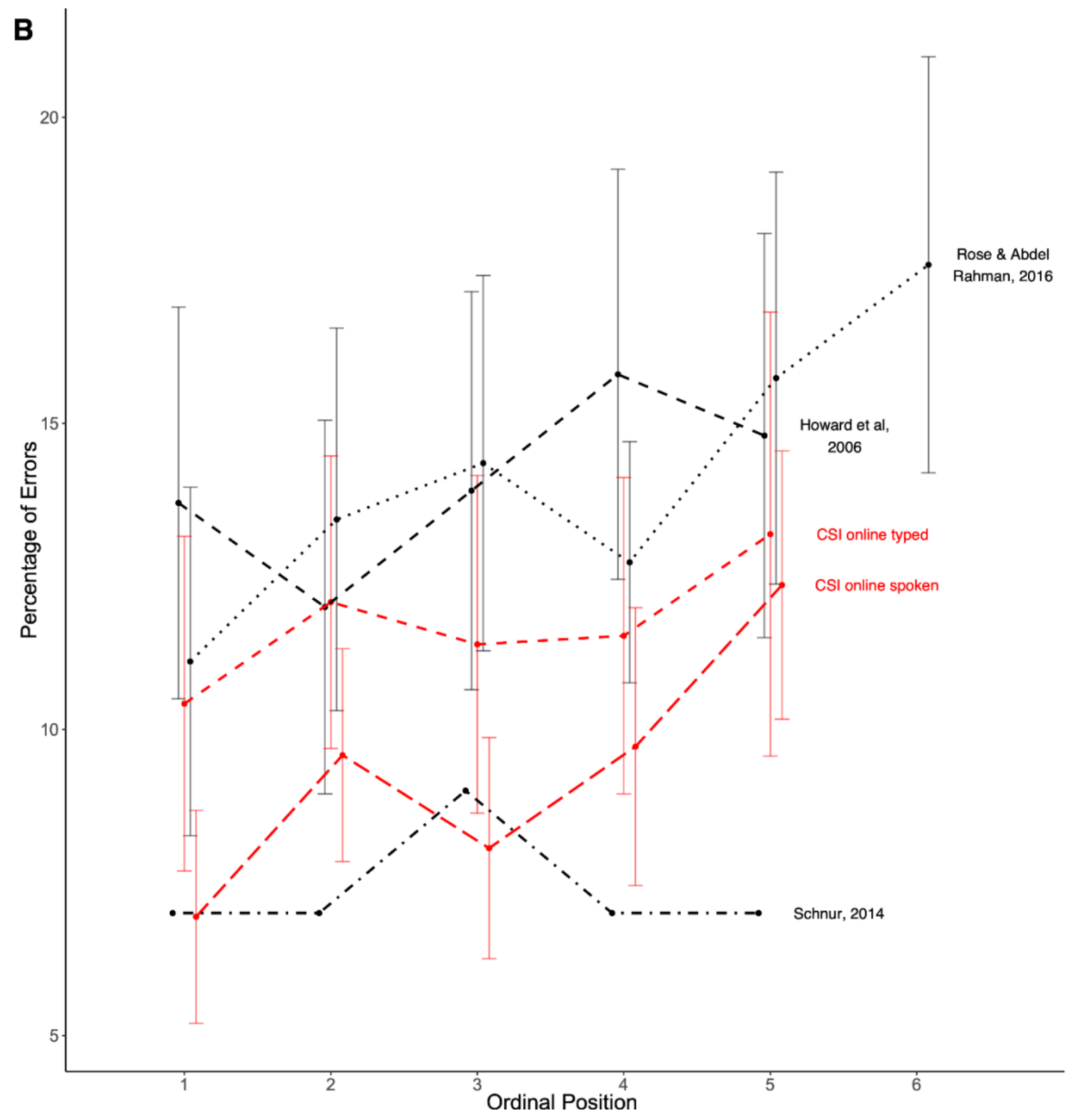

Note. The lab-based studies summarized here are the following: Costa et al., 2009 (only RTs); Howard et al., 2006; Hughes \& Schnur, 2017 (only RTs); Mulatti et al., 2014 (only RTs); Rose \& Abdel Rahman, 2016; Schnur, 2014. A detailed comparison of online and lab-based studies can be found in Table 6. Mean reaction times and error rates for each ordinal position were extracted from tables or plots reported in the respective papers or from raw data. Where available, error bars represent $95 \%$ within-subject confidence intervals $(\mathrm{Cl})$ around the mean. Unfortunately, the method applied for $\mathrm{Cl}$ calculation was not always available, but most studies applied the methods suggested by Loftus and Masson (1994), Masson and Loftus (2003) or Morey (2008), whose Cl sizes should be directly comparable (according to Morey, 2008). To increase the visibility of the plot, error bars where jittered around the ordinal positions. A. To report the overall CSI effect, the mean of the first ordinal position was subtracted from the respective means of the other ordinal positions. As can be seen, the effect from spoken responses in the current online study (experiment 1) is comparable to effects from labbased CSI experiments, whereas typed responses (experiment 2) resulted in a stronger cumulative semantic interference effect at a higher variance. B. As can be seen from panel $B$, the means and variances of error rates from spoken and typed responses in the current study are within the range of errors in previous lab-based experiments. Taken together, both speed and accuracy of spoken responses in the current online study (experiment 1 ) are comparable to lab-based CSI effects, whereas the typed responses (experiment 2), with a comparable accuracy, result in a numerically stronger, but more variable cumulative semantic interference effect (speed). 
Table 6

Comparison of the Current Web-Based Experiments to the Collection of Published Laboratory-Based Studies Taken up in Figure 4

\begin{tabular}{|c|c|c|c|c|c|c|c|c|c|c|c|}
\hline ID & Study & Manipulation & $\begin{array}{c}N_{\text {participants }} \\
\text { (gender; age) }\end{array}$ & Language & $\begin{array}{l}N_{\text {stimuli }}\left(n_{\text {fillers }}\right) \\
N_{\text {repetitions }}\end{array}$ & $N_{\text {categories }}$ (à $n_{\text {exemplars); lags }}$ & Stimulus type & $\begin{array}{c}\text { Max. picture } \\
\text { presentation (ISI) }\end{array}$ & $\begin{array}{l}M_{\text {latency of }} 1^{\text {st }} \\
\text { ord. pos. } \\
(95 \% \mathrm{Cl})\end{array}$ & $\begin{array}{l}M_{\text {interference }} \\
(95 \% \mathrm{Cl})\end{array}$ & Errors \\
\hline & $\begin{array}{l}\text { Exp. 1: Spoken } \\
\text { naming }\end{array}$ & Online setting & $\begin{array}{l}30 \text { (16 female; } \\
\text { aged 19-35) }\end{array}$ & German & $\begin{array}{l}120 \text { (+40 fillers); } \\
\text { no repetition }\end{array}$ & $\begin{array}{c}24(5) ; \\
\text { lags 2-8 (randomized) }\end{array}$ & $\begin{array}{l}\text { colour } \\
\text { photographs }\end{array}$ & $\begin{array}{l}2000 \mathrm{~ms} \\
\text { (ca. } 500 \mathrm{~ms})\end{array}$ & $\begin{array}{c}913 \mathrm{~ms} \\
( \pm 21)\end{array}$ & $\begin{array}{c}30.8 \mathrm{~ms} \\
( \pm 11.5)\end{array}$ & $7.7 \%$ \\
\hline & $\begin{array}{l}\text { Exp. 2: Typed } \\
\text { naming }\end{array}$ & $\begin{array}{l}\text { Typewritten CSI; online } \\
\text { setting }\end{array}$ & $\begin{array}{l}30 \text { (9 female; } \\
\text { aged 18-35) }\end{array}$ & German & $\begin{array}{l}120(+40 \text { fillers }) \\
\text { no repetition }\end{array}$ & $\begin{array}{c}24(5) ; \\
\text { lags 2-8 (randomized) }\end{array}$ & $\begin{array}{c}\text { colour } \\
\text { photographs }\end{array}$ & $\begin{array}{c}6000 \mathrm{~ms} \\
\text { (ca. } 500 \mathrm{~ms})\end{array}$ & $\begin{array}{c}1152 \mathrm{~ms} \\
( \pm 34)\end{array}$ & $\begin{array}{c}41.7 \mathrm{~ms} \\
( \pm 13.4)\end{array}$ & $10.9 \%$ \\
\hline 1 & $\begin{array}{l}\text { Costa et al., } \\
2009\end{array}$ & $\begin{array}{l}\text { ERPs and time course of } \\
\qquad \mathrm{CSI}\end{array}$ & $\begin{array}{c}24 \\
\text { (aged 18-25) }\end{array}$ & Spanish & $\begin{array}{l}120(+40 \text { fillers }) \\
3 \text { repetitions } \\
\rightarrow \text { overlap: } 28 \%\end{array}$ & $\begin{array}{l}24(5) ; \\
\text { lags 2-7 (randomized) } \\
\rightarrow \text { overlap: } 63 \%\end{array}$ & $\begin{array}{l}\text { black and } \\
\text { white line } \\
\text { drawings }\end{array}$ & $\begin{array}{l}1500 \mathrm{~ms} \\
(2000 \mathrm{~ms})\end{array}$ & $\begin{array}{c}809 \mathrm{~ms} \\
( \pm 20)\end{array}$ & $13.2 \mathrm{~ms}$ & $8.7 \%$ \\
\hline 2 & $\begin{array}{l}\text { Howard et al., } \\
2006\end{array}$ & $\begin{array}{l}\text { Orthogonalizing lag and } \\
\text { ordinal position effects }\end{array}$ & $\begin{array}{l}24 \text { (17 female; } \\
\text { aged 18-38) }\end{array}$ & English & $\begin{array}{l}120(+40 \text { filler }) \\
\text { no repetition } \\
\rightarrow \text { overlap: } 29 \%\end{array}$ & $\begin{array}{c}24(5) \\
\text { lags 2, 4, 6, } 8 \text { (balanced) } \\
\rightarrow \text { overlap: } 58 \%\end{array}$ & $\begin{array}{c}\text { colour } \\
\text { photographs }\end{array}$ & $\begin{array}{l}2000 \mathrm{~ms} \\
(1250 \mathrm{~ms})\end{array}$ & $\begin{array}{c}610 \mathrm{~ms} \\
( \pm 23)\end{array}$ & $\begin{array}{c}30.0 \mathrm{~ms} \\
( \pm 8.2)\end{array}$ & $22.3 \%$ \\
\hline 3 & $\begin{array}{l}\text { Hughes \& Schnur, } \\
2017 \text { (Exp. 1) }\end{array}$ & $\begin{array}{l}\text { Correlating semantic } \\
\text { blocking, CSI, and } \\
\text { picture-picture priming }\end{array}$ & 71 & English & $\begin{array}{c}\quad 60 ; \\
\text { no repetition } \\
\rightarrow \text { overlap: } 16 \%\end{array}$ & $\begin{array}{c}12(5) ; \\
\quad \text { lag } 2 \\
\rightarrow \text { overlap: } 25 \%\end{array}$ & $\begin{array}{c}\text { colour } \\
\text { photographs }\end{array}$ & $\begin{array}{l}1600 \mathrm{~ms} \\
(1000 \mathrm{~ms})\end{array}$ & $\begin{array}{c}860 \mathrm{~ms} \\
( \pm 12)\end{array}$ & $\begin{array}{c}15.1 \mathrm{~ms} \\
(S D=13.8)\end{array}$ & $15.5 \%$ \\
\hline 4 & $\begin{array}{l}\text { Mulatti et al., } \\
2014 \\
\text { (young ppt.) }\end{array}$ & $\begin{array}{c}\mathrm{CSI}+\text { repetition priming } \\
\text { in elderly (with } \mathrm{MCl} \text { ) and } \\
\text { young ppt. }\end{array}$ & $\begin{array}{l}23 \text { (19 female; } \\
\text { aged 19-25) }\end{array}$ & Italian & $\begin{array}{c}60 \text { (+28 filler); } \\
1 \text { repetition } \\
\rightarrow \text { overlap: } 22 \%\end{array}$ & $\begin{array}{c}12(5) \\
\text { lags 2, 4, } 6,8 \text { (balanced) } \\
\rightarrow \text { overlap: } 46 \%\end{array}$ & $N A$ & $\begin{array}{l}3000 \mathrm{~ms} \\
(1400 \mathrm{~ms})\end{array}$ & $700 \mathrm{~ms}$ & $31.3 \mathrm{~ms}$ & $\begin{array}{l}8.3 \% \\
\text { (across } \\
\text { groups) }\end{array}$ \\
\hline 5 & $\begin{array}{c}\text { Rose \& Abdel } \\
\text { Rahman, } 2016 \\
\text { (close relation; } \\
1^{\text {st }} \text { repetition only) }\end{array}$ & $\begin{array}{l}\text { CSI effect in close vs } \\
\text { distant semantic relations } \\
\text { in RTs and ERPs }\end{array}$ & $\begin{array}{c}24 \\
\text { (aged 20-39) }\end{array}$ & German & $\begin{array}{c}108(+108 \text { in distant } \\
\text { condition }+84 \text { filler }) ; \\
3 \text { repetitions } \\
\rightarrow \text { overlap: up to } 71 \% *\end{array}$ & $\begin{array}{l}18(6)(+18 \text { per ppt. in } \\
\text { distant condition); } \\
\text { lags } 2-8 \text { (randomized) } \\
\rightarrow \text { overlap: up to } 49 \%{ }^{*}\end{array}$ & $\begin{array}{c}\text { colour } \\
\text { photographs }\end{array}$ & $\begin{array}{l}2000 \mathrm{~ms} \\
(2000 \mathrm{~ms})\end{array}$ & $\begin{array}{l}973 \mathrm{~ms} \\
( \pm 28)\end{array}$ & $\begin{array}{c}20.0 \mathrm{~ms} \\
( \pm 10.1)\end{array}$ & $9.1 \%$ \\
\hline 6 & $\begin{array}{c}\text { Schnur, } 2014 \\
\text { (Exp. 1, short RSI) }\end{array}$ & $\begin{array}{l}\text { Replicate Howard et al., } \\
2006 \text {; long vs short RSI }\end{array}$ & 24 & English & $\begin{array}{l}120 \text { (+52 fillers); } \\
\text { no repetition } \\
\rightarrow \text { overlap: } 26 \%\end{array}$ & $\begin{array}{c}24(5) \\
\text { lags 2, 4, 6, } 8 \text { (balanced) } \\
\rightarrow \text { overlap: } 58 \%\end{array}$ & line drawings & $\begin{array}{l}2000 \mathrm{~ms} \\
(750 \mathrm{~ms})\end{array}$ & $866 \mathrm{~ms}$ & $\begin{array}{l}14.2 \mathrm{~ms}^{* *} \\
( \pm 7.7)\end{array}$ & $<12.9 \%^{* *}$ \\
\hline
\end{tabular}

Note. All cited studies report a significant cumulative semantic interference by ordinal position. All relevant studies found no effect of lag (studies $2,4,6)$. Only experiment 1 of the present study and study 5 show a statistically significant effect of ordinal position on error rates. Lags = Number of intervening stimuli between exemplars of one category; ISI =

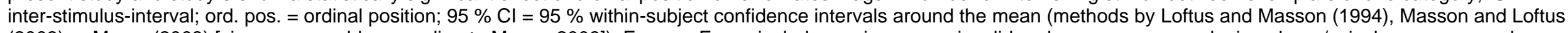
(2003) or Morey (2008) [sizes comparable according to Morey, 2008]). Errors = Errors include naming errors, invalid and no-responses and microphone/voicekey errors; overlap = percentage of stimuli/category (respectively) shared with the material used in the current study; $\mathrm{ERPs}=$ event-related potentials; $\mathrm{MCl}=$ mild $\mathrm{cognitive}$ impairment; $\mathrm{RSI}=$ responsestimulus-interval. * - up to because, across participants, all stimuli appear in close and distant semantic conditions; ${ }^{* *}$ - across both RSIs.

Missing information was not available. 


\section{Post-hoc Power Analyses}

To inform future online language production experiments, we conducted post-hoc power analyses for RT effects at different sample sizes and category numbers using the powerCurve function of the simr package in $\mathrm{R}$ (Green \& MacLeod, 2016). As the function did not work for the GLMMs with Gamma distributions used in our main analyses, we log-transformed the RT data and used a linear mixed model instead. Otherwise, the models were kept identical ${ }^{3}$ and the experimental effect sizes were used (experiment 1: Estimate $\log (\mathrm{RT})=0.028$, $p_{\text {Satterthwaite }}<.001$; experiment 2: Estimate $\left._{\log (\mathrm{RT})}=0.030, p_{\text {Satterthwaite }}<.001\right)$. For each estimation the number of simulations was $n=1000$.
Figure 5 shows the estimated power for increasing category and sample sizes of experiments 1 and 2 . The resulting total number of trials for each of the analyses is displayed in Table 7. The power estimations at different samples sizes were almost identical for both experiments, but relatively higher at smaller category sizes for typed than for spoken responses. Both experiments ( 30 subjects and 24 categories à 5 exemplars) yielded significant results in each of the 1000 simulations. Power, i.e., the percentage of significant results assuming that the effect is actually there, started to decrease with 10 subjects and 24 categories or 30 subjects and 8 categories (1200 trials each before trial exclusion), and dropped below $80 \%$ with 6 subjects in both response modalities or 6 categories in the spoken naming task

\section{Figure 5}

Results of the Post-hoc Power Analysis for the Fixed Effect of Ordinal Position at Varying Sample Sizes $(A)$ and Category Numbers $(B)$ in Experiments 1 and 2
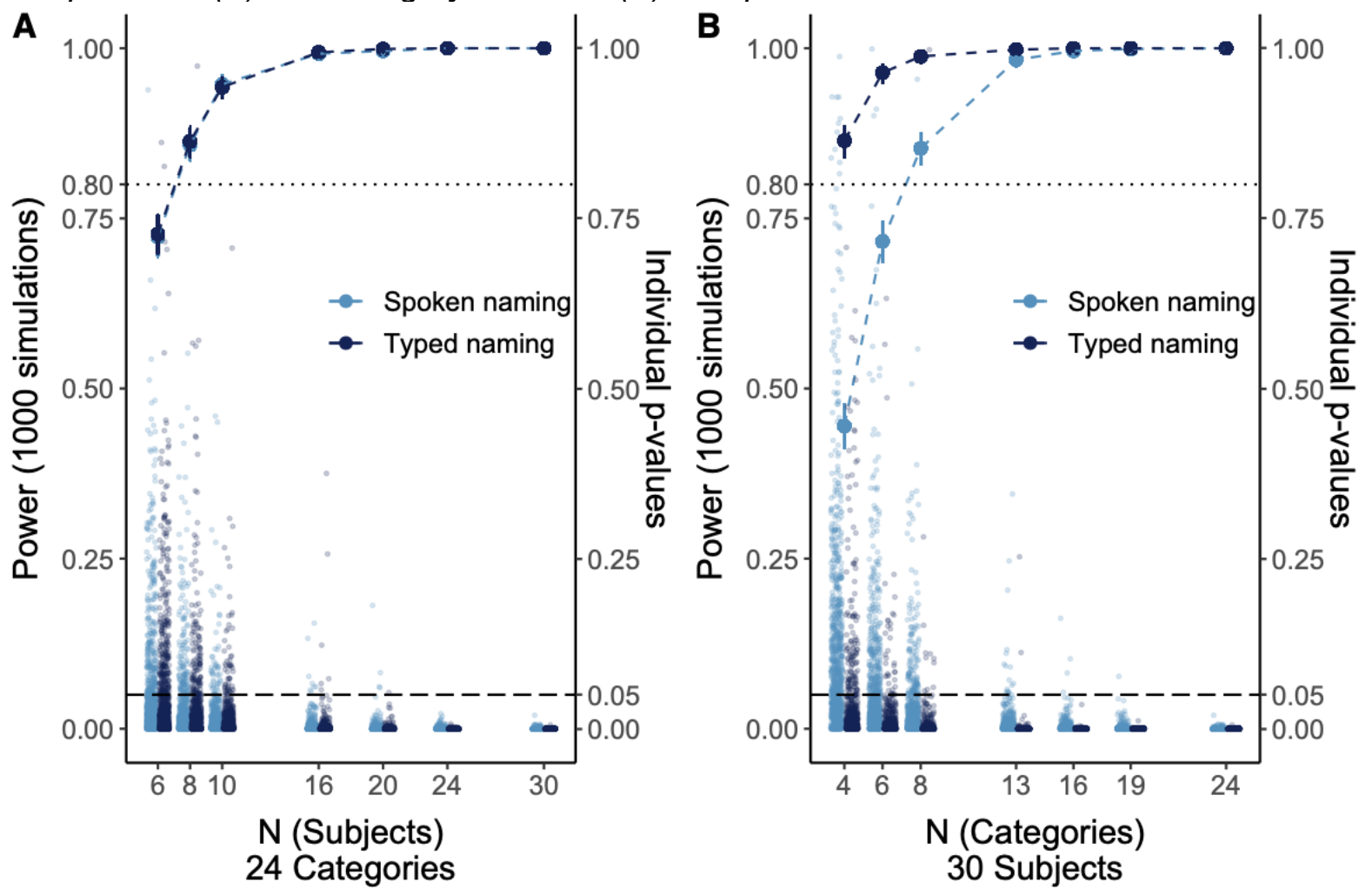

Note. Plots show the estimated power, i.e., the percentage of significant effects assuming that the effect is there, at (A) different sample sizes (and 24 categories) and (B) different numbers of categories (and a sample size of 30 participants). The line graphs show the estimated power for spoken (turquoise/light grey) and typed naming (dark blue/dark gray) with vertical lines representing

\footnotetext{
${ }^{3}$ With the only difference that the model for typewritten responses converged only after the number of iterations was increased to $2^{*} 10^{\wedge} 5$ and
} 
the $95 \%$ confidence interval around the mean. The dotted horizontal line represents a power of $80 \%$. The jittered dots represent the $p$-values for each of the 1000 simulations, and the dashed horizontal line represents a $p$-value of .05, the cut-off for a simulation to be considered significant. $X$-axis breaks were chosen such as the combinations of subjects and categories result in similar numbers of trials in estimations displayed in plots A and B, respectively (see Table 7). 24 categories and 30 participants, the break on the far right in both plots, is the actual post-hoc power of the experiments.

\section{Table 7}

Numbers of Trials (Before Trial Exclusion) at Different Sample Sizes and Numbers of Categories

\begin{tabular}{ccccccc}
\hline \multicolumn{2}{c}{ Varying number of subjects } & & \multicolumn{3}{c}{ Varying number of categories } \\
\cline { 6 - 7 } \cline { 5 - 7 } $\begin{array}{c}n \\
\text { (Subjects) }\end{array}$ & $\begin{array}{c}n \\
\text { (Categorie } \\
\text { s) }\end{array}$ & $\begin{array}{c}\text { Total } N \\
\text { trials }\end{array}$ & & $\begin{array}{c}n \\
\text { (Subjects) }\end{array}$ & $\begin{array}{c}n \\
\text { (Categorie } \\
\text { s) }\end{array}$ & $\begin{array}{c}\text { Total } N \\
\text { trials }\end{array}$ \\
\hline 30 & 24 & 3200 & 30 & 24 & 3200 \\
24 & 24 & 2880 & & 30 & 19 & 2850 \\
20 & 24 & 2400 & & 30 & 16 & 2400 \\
16 & 24 & 1920 & & 30 & 13 & 1950 \\
10 & 24 & 1200 & & 30 & 8 & 1200 \\
8 & 24 & 960 & & 30 & 6 & 900 \\
6 & 24 & 720 & 30 & 4 & 750 \\
\hline
\end{tabular}




\section{Discussion}

In this study, we set out to replicate the cumulative semantic interference (CSI) effect in a web-based setting, comparing two response modalities for feasibility and validity, namely spoken and typed responses. A stable effect in lab-based language production research, the CSI effect is elicited for each new member of a previously presented category in the continuous naming paradigm with consecutive naming of seemingly unrelated pictures. In the two experiments presented here, we ran the CSI paradigm through participants' web browsers using the platform SoSci Survey. In experiment 1, the participants' microphones were accessed, and their spoken responses were recorded through a JavaScript implementation. In experiment 2, the first keystroke of each typed target word was used as the response variable, which was assessed by a custom JavaScript plugin (Stark, 2021b). In both online experiments, we were able to replicate the linear increase in reaction times for each additional category member. Additional exploratory analyses showed that error rates also increased for additional category members in spoken, but not in typed responses. Although a direct comparison between lab-based and online assessment was not performed we show that, overall, both speed and accuracy match well with previous lab-based studies. Our results thereby add to the growing body of evidence that language production research can be conducted in online settings (Fairs \& Strijkers, 2021; Vogt et al., 2021). Moreover, we show that measures of typewritten responses provide a valuable tool for online language production research which can be automatically analysed, thus reducing workload and time investment for data processing.

\section{Comparison Between Different Response Modalities (Spoken / Type- written)}

The results of experiment 1 using overt spoken responses revealed a stable CSI effect with a linear trend of $\sim 31 \mathrm{~ms}$. Moreover, an analysis of overall errors revealed a significant increase in error rates across ordinal positions. The effect is quite large, which may be related to the use of semantic subcategories with closely related items. Such narrow categories have been shown to result in stronger CSI effects compared to main categories with distantly related items (Rose \& Abdel Rahman, 2016). Moreover, the randomization in our design was done within blocks of categories, rather than across the whole stimulus list, leading to a slight predominance of short compared to long lags between category members, which may additionally have increased the effect, although previous research suggests that lag does not strongly affect the linear increase of reaction times in the CSI paradigm (e.g., Schnur, 2014)

In experiment 2, we assessed typing as an alternative response modality to measure reaction times in language production research. Both handwritten and typewritten responses have previously been used in picture naming experiments (Baus et al., 2013; Bonin et al., 2002; Pinet et al., 2015, 2016a; Qu et al., 2016; Qu \& Damian, 2020; Torrance et al., 2018; Zhang \& Damian, 2010). However, to the best of our knowledge, no study using typewritten responses has tested semantic interference effects. Our study is therefore the first to provide evidence on this response modality in a reaction time-dependent semantic interference task such as the CSI paradigm. We find a strong and stable CSI effect also for typed responses. This effect of $\sim 42 \mathrm{~ms}$ per ordinal position is numerically even stronger when compared to experiment 1 (spoken responses) and to comparable labbased CSI experiments. Moreover the effect shows a larger variance, and typed responses were overall much slower than spoken responses (by $\sim 100 \mathrm{~ms}$ ). The latter is in line with previous reports (e.g., Bonin \& Fayol, 2000). Additionally, latency differences in the present study may stem from the different stimulus familiarization procedures in experiments 1 and 2 . In the spoken naming task, participants saw the pictures in groups of eight pictures each and proceeded in a self-paced manner, while in the typewritten naming task, participants were familiarized with the pictures individually and typed each picture name. Research suggests that the overt production of the picture names may lead to deeper processing of both the visual details and the verbal labels of pictures (Hourihan \& 
Churchill, 2020), which in turn can affect naming latencies. Yet another explanation of the longer naming latencies could be a technical one. Comparing actual keystroke latencies and the latencies recorded online, previous studies reported online latencies for each keypress to be $\sim 30-100$ ms slower than the actual latencies, depending on the hardware, operator system, and browser used (Pinet et al., 2017; Reimers \& Stewart, 2015). While it seems unlikely that the $\sim 100$ ms overall difference of spoken and typewritten latencies reported here can be explained uniquely by a smaller technical delay in the audio recordings, an actual comparison of lab-based and online recorded latencies is pending. Beyond these technical caveats the robust demonstration of the CSI effect for the typed modality suggests an origin at the lexicosemantic processing level independent of output modality, as proposed by most theoretical accounts of cumulative interference (e.g., Levelt et al., 1999; Roelofs, 2018). Although no primary target of the present study, similar CSI-effects between the two modalities speak for an origin at the conceptual or lexical level (Abdel Rahman \& Melinger, 2009, 2019; Howard et al., 2006; Oppenheim et al., 2010). An origin at the articulatory or word form level, as has been proposed based on picture-word interference tasks (Mahon et al., 2007; Navarrete et al., 2010) would predict substantial differences between the two modalities tested here.

While latency effects dominate in neurotypical participants, semantic interference has also been reported in increased error rates, especially in the PWI or blocked cyclic naming paradigm (e.g., Belke et al., 2005; Caramazza \& Costa, 2000; Damian et al., 2001; Gauvin et al., 2018; Starreveld \& La Heij, 2017). In the CSI task, the effect of semantic interference on error rates is still inconclusive as only some studies did find error effects by ordinal position (Howard et al., 2006; Schnur, 2014 vs. Rose \& Abdel Rahman, 2016). This may be one reason why we found an error-based CSI-effect for the spoken, but not in the typed responses. The longer overall latency for typed responses and the different quality of the potential sources of errors (e.g., keystroke accuracy due to motoric / typing skills) may have obscured the effect for typed responses in the present study. The cumulative interference in error rates for the spoken response modality, however, aligns with models assuming a lexico-semantic locus of the effect, where inhibited target retrieval may result in slower naming latencies as well as erroneous naming (Abdel Rahman \& Melinger, 2009, 2019; Levelt et al., 1999; Oppenheim et al., 2010; Roelofs, 2018; Schnur, 2014).

Taken together, these data supplement previous studies showing that effects that are already well-established in spoken naming can be found in written naming, too (Pinet \& Nozari, 2018; Torrance et al., 2018). This highlights that a number of the experimentally described effects are related to linguistic processes which support language production supra-modally. Our study shows that this holds for the CSIeffect which most plausibly arises at a level independent of the output modality. The finding is encouraging for other aspects of language production research. Notwithstanding, we may highlight that in instances which require modality-specific processing the difference is expected to be relevant. This pertains, for instance, to the assessment of articulation-related processes, or research on written language processing per se. Moreover, in elderly participants typed (as opposed to handwritten) responses may not be as fluent, an aspect which is also of great importance when including participants with an acquired brain lesion.

\section{Methodological Implications: Lab-Based CSI Effects Can be Replicated Online}

Our findings support the feasibility of collecting overt language production samples from participants at their homes, using JavaScript-based plugins which can be implemented in many online platforms. This could be particularly useful to collect data from participants across different timepoints, nationalities or social backgrounds, increasing the diversity of the sample usually included in psycholinguistic research.

It also opens the perspective to test participants with an acquired language disorder (most notably stroke-induced aphasia). Long-term follow up, especially regarding scientifically motivated questions, is often hampered by the efforts related to 
re-inviting and transporting the patient to the respective institution. As a caveat, computer competence and access to web-browsers need to be assessed in such populations. Moreover, distortions of articulation (spoken modality) and/or impairments of fine motor skills (typing) need to be respected. The fact that we showed qualitatively similar effects for both modalities is encouraging, potentially allowing for the use of the respectively less impaired modality.

In most experiments investigating keystroke latencies or typewritten responses, participants were screened for their typing abilities, restricting the analyses on skilled or expert typists (Pinet et al., 2015, 2016a; Scaltritti et al., 2017; but see also e.g., Baus et al., 2013). Our results show that refraining from such restrictions still allows for the robust demonstration of a semantic interference effect. By including the "normal" range of typing abilities, we were able to collect our participants from the same population as in experiment 1. Furthermore, the fact that the CSI effect can be found across a relatively wide range of typing abilities suggests its high reliability even in online settings. However, it should be noted that people subscribed to online experimental platforms such as Prolific are probably more experienced typers, an issue which will be of relevance in elderly populations and in people with an acquired language, cognitive and/or motor deficit. We will address this issue in a follow-up study including participants with mild to moderate aphasia.

\section{Technical Implications: Reducing Pre- Processing Efforts}

In a previous language production experiment using SoSci Survey and the JavaScript plugin described here (Vogt et al., 2021), the file lengths of the sound recordings were reported to vary between or even within participants, the reason for this variation being still unknown (for a discussion on possible reasons see below). This was the case also in the current sample. We therefore additionally assessed the interaction of ordinal position and file length ( $z$-transformed) in a statistical model. The interaction term was not significant (estimate $=4.37, S E=3.8, t=1.147, p=$ 0.251 ), meaning that variation in file lengths did not influence the effect.
Importantly, our results are encouraging regarding an aspect of pre-processing of the data. Since both options (spoken vs. typed responses) yielded similar effects, the cumbersome pre-processing of spoken responses may be eased by the use of typewritten responses in some research scenarios. Despite automated vocal onset detection through algorithms such as that provided by Chronset (Roux et al., 2017), all data has to be double-checked by the (native speaker) experimenter for accuracy of the response and the VOT, resulting in, potentially, hours or days' worth of workload. This may be especially challenging if the data quality is poorer in online when compared to the lab-based acquisition (Fairs \& Strijkers, 2021; Vogt et al., 2021), increasing the need to carefully check the data.

Within the typewritten response modality, we were able to drastically reduce data processing efforts. With a custom $\mathrm{R}$ script (Stark, 2021a) and an $R$ package with functions for comparing string inputs (van der Loo, 2014), we tested automated classification of the typed responses. As this method produced near-identical classification when compared to manual processing, and an identical statistical effect, it is an effective way to reduce workload in language production experiments. Beyond doubt, spoken production is the most relevant target. However, to make large cohort assessments possible, the typewritten response modality may complement a number of exciting research questions to be addressed in the field.

\section{Recommendations for Running Lan- guage Production Experiments Online}

Based on the two experiments reported
here, we may highlight some
recommendations for future experiments.
For both the spoken and typewritten
modality, we observed large effects at high
power. While the power remains high even
for a relatively small number of trials, our
post-hoc power analysis for the spoken
response modality suggests that the
number of trials per participant, i.e., the
number of categories in the CSI task, affects
the power more strongly than the number of
participants, confirming previous reports
(Vogt et al., 2021). Thus, a reasonable


number of trials per participant should be implemented. Paradigms with many trials and within-participant manipulations such as the CSI paradigm reported here, seem to elicit robust effects, potentially counteracting the negative effects of a less controlled setting at the participants' homes compared to a lab environment, technical disturbances or potential non-compliance. This may allow for testing more diverse populations to increase ecological validity.

For the technical implementation of both audio recordings and typewritten latencies, we recommend lean JavaScript-based implementations. JavaScript-based plugins such as the ones used and presented here are a good alternative that give researchers full control over the script. Recently, some platforms for online experiments have started to implement audio recordings already into their predefined tools and functions (e.g., Gorilla Experiment Builder, Anwyl-Irvine et al., 2020b or FindingFive, FindingFive Team, 2019). The assessment of keystroke latencies is an inbuilt feature of most JavaScript-based platforms. We have not yet tested these inbuilt features but assume that they should lead to very similar results as the custom scripts. Predefined tools and functions may thus be a good alternative for researchers who prefer easyto-handle implementations, including dragand-drop programming, rather than customizing code. Independently of the implementation used, it is important to note that from the current study we cannot draw assumptions on the actual degree of systematic bias or technical noise introduced by different hardware / software set-ups. With our fully randomized withinsubject design we were able to replicate hypothesized effects at high power despite potential noise, however this cannot be transferred to pseudo-randomized and/or between-subject designs.

In the spoken naming task, like other authors (Vogt et al., 2021), we observed some variation in audio recording file lengths. This variation did not affect the effect reported here. Still, we do not yet know the source of the variation and potentially, it may have occurred at the beginning or at the end of the recording. Therefore, researchers should pay particular attention to this potential source of noise. Crucially, only a variation at the beginning of the recordings should affect the assessment of reaction times. A simple method to improve the synchronization of the audio recording (timer for typewritten answers) and stimulus presentation is to present the stimulus and to start the recording (or timer) only after the page is fully loaded. This can be achieved by using the window.onload event in JavaScript. Although, depending on the internet connection, this may lead to some jittering of the interstimulus interval, the stimulus can be preloaded in every trial leading to a high synchronization of reaction time measurements (audio or typed) and stimulus presentation. We therefore recommend all researchers to make use of such a method.

For typewritten answers, we compared manual and automatic processing procedures and found they classified nearly all typewritten answers identically as correct or incorrect. We therefore highly recommend such automatic classification procedures. However, researchers should decide a priori which classification procedure to use and which cut-off criterion to apply. Different procedures exist that are specialized for different typewritten answers, such as longer texts and or single words. We recommend Bosker (Bosker, 2021) and van der Loo (van der Loo, 2014) as overview articles. We found that the Jarodistance (Jaro, 1989, 1995), a method specialized for short answers, lead to good results with a cut-off criterion of $d=.3$. The even more widely known Levenshtein distance (Levenshtein, 1966; all operations equally weighted; cut-off criterion $d=.3$ ) and the optimal string alignment procedure (restricted Damerau Levenshtein distance; all operations equally weighted; cut-off criterion $d=.3$ ) as implemented in the stringdist package also led to very good, though slightly more conservative, results (see Appendix B). Furthermore, researchers must provide the algorithms with accepted naming alternatives (e.g., "sofa" instead of "couch"). In the best case, these lists can be compiled based on previous experiments. If no such prior data exists, researchers should carefully check their data after the classification. Beyond such caveats, using automated classification procedures not only reduces the time needed for data preprocessing from hours to seconds (Borrie et 
al., 2019), it also increases the interrater reliability. For a follow-up experiment, we even implemented these simple methods into the experiment itself, in order to provide feedback on the typing accuracy already during the experiment. Before running an experiment with typewritten responses, researchers must decide whether participants' typed answers should be displayed on the screen and whether participants are allowed to correct their typewritten answers by using the backspace key. Displaying participants answers on the screen can both affect naming latencies (Perret \& Laganaro, 2013; Snyder et al., 2015) and error types (Pinet \& Nozari, 2020, 2021). However, in online settings, we assume that giving no feedback at all may reduce adherence to the task. Anecdotal evidence suggests that allowing corrections in typewritten answers is more similar to natural typing behaviour, but it may result in different overall typing duration. If, like in our case, researchers are most interested in typing onset times, they may decide to allow corrections in typewritten answers. If, by contrast, researchers are interested in interkeystroke intervals and overall typing duration, they may decide not to allow corrections.

Last but not least, we recommend restricting the use of different keyboard types. Often, one keyboard type has direct key bindings for all letters of a language while others do not. This can affect the number of keys that need to be pressed to type a specific word and the motor preparation stages if the

\section{References}

Abdel Rahman, R., \& Aristei, S. (2010). Now you see it . . . and now again: Semantic interference reflects lexical competition in speech production with and without articulation. Psychonomic Bulletin and Review, 17(5), 657-661. https://doi.org/10.3758/PBR.17.5.657

Abdel Rahman, R., \& Melinger, A. (2009). Semantic context effects in language production: A swinging lexical network proposal and a review. Language and Cognitive Processes, 24(5), 713-734. https://doi.org/10.1080/016909608025972 50

Abdel Rahman, R., \& Melinger, A. (2019). Semantic processing during language production: an update of the swinging same letter is to be pressed with different hands on different keyboards (Pinet et al., 2016a). Together with our script to assess typing latencies, we provide one example how the keyboard type can be assessed. Next to restricting the keyboard type, at least for languages including accents or capitalization at the beginning of a word, we recommend instructing participants to use the caps lock key and to write all letters in upper case.

\section{Conclusion}

Running experiments online opens new perspectives for assessing more diverse populations across different linguistic, social or generational backgrounds. Our study adds evidence to the feasibility of implementing reaction-time sensitive language production experiments in webbased settings. This allows for running cross-linguistic, cross-sectional or longitudinal studies which may have limited practicability in in-person, lab-based settings. Moreover, we show that typewritten responses are a valid, practical alternative to collecting overt spoken responses through participants' microphones. Automatic processing can further reduce the workload of processing the typewritten answers. By highlighting important technical and conceptual considerations, we hope to have provided recommendations for an easy access to studying both typewritten and spoken language production online.

lexical network. Language, Cognition and Neuroscience, 34(9), 1176-1192.

https://doi.org/10.1080/23273798.2019.15 99970

Anwyl-Irvine, A., Dalmaijer, E. S., Hodges, N., \& Evershed, J. K. (2020a). Realistic precision and accuracy of online experiment platforms, web browsers, and devices. Behavior Research Methods, 1-22. https://doi.org/10.3758/s13428-02001501-5

Anwyl-Irvine, A. L., Massonnié, J., Flitton, A., Kirkham, N., \& Evershed, J. K. (2020b). Gorilla in our midst: An online behavioral experiment builder. Behavior Research Methods, 52(1), 388-407.

https://doi.org/10.3758/s13428-01901237-x 
Baker, D. H., Vilidaite, G., Lygo, F. A., Smith, A. K., Flack, T. R., Gouws, A. D., \& Andrews, T. J. (2020). Power contours: Optimising sample size and precision in experimental psychology and human neuroscience. Psychological

Methods. https://doi.org/10.1037/met0000337

Barr, D. J., Levy, R., Scheepers, C., \& Tily, H. J. (2013). Random effects structure for confirmatory hypothesis testing: Keep it maximal. Journal of Memory and Language, 68(3), 255-278.

https://doi.org/10.1016/j.jml.2012.11.001

Bates, D., Mächler, M., Bolker, B., \& Walker, S. (2014). Fitting linear mixed-effects models using Ime4. Journal of Statistical Software, 67(1), 1-48. https://doi.org/10.18637/jss.v067.i01

Baus, C., Strijkers, K., \& Costa, A. (2013). When does word frequency influence written production? Frontiers in Psychology, 4(DEC), 1-9. https://doi.org/10.3389/fpsyg.2013.00963

Belke, E., Meyer, A. S., \& Damian, M. F. (2005). Refractory effects in picture naming as assessed in a semantic blocking paradigm. The Quarterly Journal of Experimental Psychology Section A, 58(4), 667-692. https://doi.org/10.1080/027249804430001 42

Bertram, R., Tønnessen, F. E., Strömqvist, S., Hyönä, J., \& Niemi, P. (2015). Cascaded processing in written compound word production. Frontiers in Human Neuroscience, 9(APR), 1-10.

https://doi.org/10.3389/fnhum.2015.00207

Boersma, P., \& Weenink, D. (2020). Praat: doing phonetics by computer (6.1.16).

Bonin, P., Chalard, M., Méot, A., \& Fayol, M. (2002). The determinants of spoken and written picture naming latencies. British Journal of Psychology, 93(1), 89-114. https://doi.org/10.1348/000712602162463

Bonin, P., \& Fayol, M. (2000). Writing words from pictures: What representations are activated, and when? Memory \& Cognition, 28(4), 677-689. https://doi.org/10.3758/BF03201257

Borrie, S. A., Barrett, T. S., \& Yoho, S. E. (2019). Autoscore: An open-source automated tool for scoring listener perception of speech. The Journal of the Acoustical Society of America, 145(1), 392-399. https://doi.org/10.1121/1.5087276

Bosker, H. R. (2021). Using fuzzy string matching for automated assessment of listener transcripts in speech intelligibility studies. Behavior Research Methods. https://doi.org/10.3758/s13428-021-

01542-4
Brandt, D. (2015). The Rise of Writing. Cambridge University Press. https://doi.org/10.1017/CBO978131610637 2

Brauer, M., \& Curtin, J. J. (2018). Linear mixedeffects models and the analysis of nonindependent data: A unified framework to analyze categorical and continuous independent variables that vary withinsubjects and/or within-items. Psychological Methods, 23(3), 389-411.

https://doi.org/10.1037/met0000159

Breining, B., Nozari, N., \& Rapp, B. (2016). Does segmental overlap help or hurt? Evidence from blocked cyclic naming in spoken and written production. Psychonomic Bulletin \& Review, 23(2), 500-506. https://doi.org/10.3758/s13423-015-0900$x$

Bridges, D., Pitiot, A., MacAskill, M. R., \& Peirce, J. W. (2020). The timing mega-study: Comparing a range of experiment generators, both lab-based and online. PeerJ, 8, 1-29.

https://doi.org/10.7717/peerj.9414

Bürki, A., Elbuy, S., Madec, S., \& Vasishth, S. (2020). What did we learn from forty years of research on semantic interference? A Bayesian meta-analysis. Journal of Memory and Language, 114(April), 104125. https://doi.org/10.1016/j.jml.2020.104125

Caramazza, A., \& Costa, A. (2000). The semantic interference effect in the pictureword interference paradigm: Does the response set matter? Cognition, 75(2), 5164.https://doi.org/10.1016/S00100277(99)00082-7

Chen, J.-Y., \& Li, C.-Y. (2011). Word form encoding in Chinese word naming and word typing. Cognition, 121(1), 140-146. https://doi.org/10.1016/j.cognition.2011.05 .009

Costa, A., Strijkers, K., Martin, C., \& Thierry, G. (2009). The time course of word retrieval revealed by event-related brain potentials during overt speech. Proceedings of the National Academy of Sciences of the United States of America, 106(50), 2144221446.

https://doi.org/10.1073/pnas.0908921106

Crump, M. J. C., \& Logan, G. D. (2010). Hierarchical control and skilled typing: Evidence for word-level control over the execution of individual keystrokes. Journal of Experimental Psychology: Learning, Memory, and Cognition, 36(6), 1369-1380. https://doi.org/10.1037/a0020696

Damian, M. F., Vigliocco, G., \& Levelt, W. J. M. (2001). Effects of semantic context in the naming of pictures and words. Cognition, $81,77-86$. 
de Leeuw, J. R. (2015). jsPsych: A JavaScript library for creating behavioral experiments in a Web browser. Behavior Research Methods, 47(1), 1-12. https://doi.org/10.3758/s13428-014-0458$\mathrm{y}$

Fairs, A., \& Strijkers, K. (2021). Can we use the internet to study speech production? Yes we can! Evidence contrasting online versus laboratory naming latencies and errors. PsyArXiv.

https://doi.org/10.31234/osf.io/2bu4c

FindingFive Team. (2019). FindingFive: $A$ web platform for creating, running, and managing your studies in one place. FindingFive Corporation (nonprofit).

Gallant, J., \& Libben, G. (2019). No lab, no problem: Designing lexical comprehension and production experiments using PsychoPy3. The Mental Lexicon, 14(1), 152-168.

https://doi.org/10.1075/ml.00002.gal

Gauvin, H. S., Jonen, M. K., Choi, J., McMahon, K. L., \& de Zubicaray, G. I. (2018). No lexical competition without priming: Evidence from the picture-word interference paradigm. Quarterly Journal of Experimental Psychology, 71(12), 25622570.

https://doi.org/10.1177/174702181774726 6

Gilquin, G. (2010). Language production: A window to the mind? In H. Götzsche (Ed.), Memory, Mind and Language (pp. 89102). Cambridge Scholar Publishing.

Green, P., \& MacLeod, C. J. (2016). SIMR: An R package for power analysis of generalized linear mixed models by simulation. Methods in Ecology and Evolution, 7(4), 493-498. https://doi.org/10.1111/2041$210 X .12504$

Grootswagers, T. (2020). A primer on running human behavioural experiments online. Behavior Research Methods, 52(6), 22832286. https://doi.org/10.3758/s13428-02001395-3

Henrich, J., Heine, S. J., \& Norenzayan, A. (2010). The weirdest people in the world? Behavioral and Brain Sciences, 33(2-3), 61-83.

https://doi.org/10.1017/S0140525X099915 $2 \mathrm{X}$

Higashiyama, Y., Takeda, K., Someya, Y., Kuroiwa, Y., \& Tanaka, F. (2015). The neural basis of typewriting: A functional MRI study. PLOS ONE, 10(7), e0134131. https://doi.org/10.1371/journal.pone.01341 31

Hope, R. M. (2013). Rmisc: Ryan Miscellaneous.

Hourihan, K. L., \& Churchill, L. A. (2020). Production of picture names improves picture recognition. Canadian Journal of
Experimental Psychology/Revue

Canadienne de Psychologie

Expérimentale, 74(1), 35-43.

https://doi.org/10.1037/cep0000185

Howard, D., Nickels, L., Coltheart, M., \& ColeVirtue, J. (2006). Cumulative semantic inhibition in picture naming: Experimental and computational studies. Cognition, 100(3), 464-482.

https://doi.org/10.1016/j.cognition.2005.02 .006

Hughes, J. W., \& Schnur, T. T. (2017). Facilitation and interference in naming: $A$ consequence of the same learning process? Cognition, 165, 61-72.

https://doi.org/10.1016/J.COGNITION.201 7.04.012

Jaro, M. A. (1989). Advances in record-linkage methodology as applied to matching the 1985 census of Tampa, Florida. Journal of the American Statistical Association, 84(406), 414-420.

https://doi.org/10.1080/01621459.1989.10 478785

Jaro, M. A. (1995). Probabilistic linkage of large public health data files. Statistics in Medicine, 14(5-7), 491-498. https://doi.org/10.1002/sim.4780140510

Khan, M. (2020). RecordRTC. https://github.com/muaz-khan/RecordRTC

Kim, K. S., Wang, H., \& Max, L. (2020). It's about time: Minimizing hardware and software latencies in speech research with real-time auditory feedback. Journal of Speech, Language, and Hearing Research, 63(8), 2522-2534.

https://doi.org/10.1044/2020_JSLHR-1900419

Krantz, J. H., \& Reips, U.-D. (2017). The state of web-based research: A survey and call for inclusion in curricula. Behavior Research Methods, 49(5), 1621-1629. https://doi.org/10.3758/s13428-017-0882$x$

Leiner, D. J. (2019). SoSci Survey (Version 3.1.06).

Levelt, W. J. M., Roelofs, A., \& Meyer, A. S. (1999). A theory of lexical access in speech production. Behavioural and Brain Sciences, 22, 1-75. https://doi.org/10.3115/992628.992631

Levenshtein, V. I. (1966). Binary codes capable of correcting deletions, insertions, and reversals. Soviet Physics-Doklady, 10(8), 707-710.

Lo, S., \& Andrews, S. (2015). To transform or not to transform: using generalized linear mixed models to analyse reaction time data. Frontiers in Psychology, 6, 1171. https://doi.org/10.3389/fpsyg.2015.01171 
Loftus, G. R., \& Masson, M. E. J. (1994). Using confidence intervals in within-subject designs. Psychonomic Bulletin \& Review, 1(4), 476-490. https://doi.org/10.3758/BF03210951

Logan, G. D., \& Crump, M. J. C. (2011). Hierarchical control of cognitive processes: The case of skilled typewriting. In Psychology of Learning and Motivation Advances in Research and Theory (1st ed., Vol. 54, pp. 1-27). Elsevier Inc. https://doi.org/10.1016/B978-0-12385527-5.00001-2

Lupker, S. J. (1979). The semantic nature of response competition in the picture-word interference task. Memory \& Cognition, 7(6), 485-495.

https://doi.org/10.3758/BF03198265

Mahon, B. Z., Costa, A., Peterson, R., Vargas, K. A., \& Caramazza, A. (2007). Lexical selection is not by competition: $A$ reinterpretation of semantic interference and facilitation effects in the Picture-Word Interference paradigm. Journal of Experimental Psychology: Learning Memory and Cognition, 33(3), 503-535. https://doi.org/10.1037/02787393.33.3.503

Masson, M. E. J., \& Loftus, G. R. (2003). Using confidence intervals for graphically based data interpretation. In Canadian Journal of Experimental Psychology/Revue canadienne de psychologie expérimentale (Vol. 57, Issue 3, pp. 203-220). Canadian Psychological https://doi.org/10.1037/h0087426

Mathôt, S., \& March, J. (2021). Conducting linguistic experiments online with OpenSesame and OSWeb.

https://doi.org/doi.org/10.31234/osf.io/wnr yc

Morey, R. D. (2008). Confidence Intervals from Normalized Data: A correction to Cousineau (2005). Tutorials in Quantitative Methods for Psychology, 4(2), 61-64. https://doi.org/10.20982/tqmp.04.2.p061

Mulatti, C., Calia, C., De Caro, M. F., \& Della Sala, S. (2014). The cumulative semantic interference effect in normal and pathological ageing. Neuropsychologia, $65,125-130$.

https://doi.org/10.1016/j.neuropsychologia .2014.10.007

Navarrete, E., Mahon, B. Z., \& Caramazza, A. (2010). The cumulative semantic cost does not reflect lexical selection by competition. Acta Psychologica, 134(3), 279-289. https://doi.org/10.1016/J.ACTPSY.2010.0 2.009
Navarro, G. (2001). A guided tour to approximate string matching. $A C M$ Computing Surveys, 33(1), 31-88. https://doi.org/10.1145/375360.375365

Oppenheim, G. M., Dell, G. S., \& Schwartz, M. F. (2010). The dark side of incremental learning: A model of cumulative semantic interference during lexical access in speech production. Cognition, 114(2), 227-252.

https://doi.org/10.1016/j.cognition.2009.09 .00

Palan, S., \& Schitter, C. (2018). Prolific.ac-A subject pool for online experiments. Journal of Behavioral and Experimental Finance, 17, 22-27. https://doi.org/10.1016/j.jbef.2017.12.004

Peer, E., Brandimarte, L., Samat, S., \& Acquisti, A. (2017). Beyond the Turk: Alternative platforms for crowdsourcing behavioral research. Journal of Experimental Social Psychology, 70, 153-163. https://doi.org/10.1016/j.jesp.2017.01.006

Perret, C., \& Laganaro, M. (2013). Why are written picture naming latencies (not) longer than spoken naming? Reading and Writing, 26(2), 225-239. https://doi.org/10.1007/s11145-012-93658

Pickering, M. J., \& Garrod, S. (2013). An integrated theory of language production and comprehension. Behavioral and Brain Sciences, 36(04), 329-347. https://doi.org/10.1017/S0140525X120014 95

Pinet, S., Dubarry, A.-S., \& Alario, F.-X. (2016a). Response retrieval and motor planning during typing. Brain and Language, 159, 74-83.

https://doi.org/10.1016/j.bandl.2016.05.01 2

Pinet, S., Hamamé, C. M., Longcamp, M., Vidal, F., \& Alario, F. X. (2015). Response planning in word typing: Evidence for inhibition. Psychophysiology, 52(4), 524531. https://doi.org/10.1111/psyp.12373

Pinet, S., \& Nozari, N. (2018). "Twisting fingers": The case for interactivity in typed language production. Psychonomic Bulletin \& Review, 25(4), 1449-1457. https://doi.org/10.3758/s13423-018-14527

Pinet, S., \& Nozari, N. (2020). Electrophysiological correlates of monitoring in typing with and without visual feedback. Journal of Cognitive Neuroscience, 32(4), 603-620. https://doi.org/10.1162/jocn_a_01500 
Pinet, S., \& Nozari, N. (2021). The role of visual feedback in detecting and correcting typing errors: A signal detection approach. Journal of Memory and Language, 117, 104193. https://doi.org/10.1016/j.jml.2020.104193

Pinet, S., Ziegler, J. C., \& Alario, F.-X. (2016b). Typing is writing: Linguistic properties modulate typing execution. Psychonomic Bulletin \& Review, 23(6), 1898-1906. https://doi.org/10.3758/s13423-016-10443

Pinet, S., Zielinski, C., Mathôt, S., Dufau, S., Alario, F.-X., \& Longcamp, M. (2017). Measuring sequences of keystrokes with jsPsych: Reliability of response times and interkeystroke intervals. Behavior Research Methods, 49(3), 1163-1176. https://doi.org/10.3758/s13428-016-07763

Qu, Q., \& Damian, M. F. (2020). An electrophysiological analysis of the time course of phonological and orthographic encoding in written word production. Language, Cognition and Neuroscience, 35(3), 360-373.

https://doi.org/10.1080/23273798.2019.16 59988

Qu, Q., Zhang, Q., \& Damian, M. F. (2016). Tracking the time course of lexical access in orthographic production: An eventrelated potential study of word frequency effects in written picture naming. Brain and Language, 159, 118-126.

https://doi.org/10.1016/j.bandl.2016.06.00 8

Qu, X., Mei, Q., Liu, P., \& Hickey, T. (2020). Using EEG to distinguish between writing and typing for the same cognitive task. In Lecture Notes in Computer Science (including subseries Lecture Notes in Artificial Intelligence and Lecture Notes in Bioinformatics): Vol. 12462 LNAI (pp. 6674). https://doi.org/10.1007/978-3-03060735-7 7

$\mathrm{R}$ Core Team. (2020). R: A language and environment for statistical computing. $\mathrm{R}$ Foundation for Statistical Computing.

Reimers, S., \& Stewart, N. (2015). Presentation and response timing accuracy in Adobe Flash and HTML5/JavaScript Web experiments. Behavior Research Methods, 47(2), 309-327. https://doi.org/10.3758/s13428-014-04711

Roelofs, A. (2018). A unified computational account of cumulative semantic, semantic blocking, and semantic distractor effects in picture naming. Cognition, 172, 59-72. https://doi.org/10.1016/j.cognition.2017.12 .007
Rose, S. B., \& Abdel Rahman, R. (2016). Semantic similarity promotes interference in the continuous naming paradigm: Behavioural and electrophysiological evidence. Language, Cognition and Neuroscience, 32(1), 55-68.

https://doi.org/10.1080/23273798.2016.12 12081

Roux, F., Armstrong, B. C., \& Carreiras, M. (2017). Chronset: An automated tool for detecting speech onset. Behavior Research Methods, 49(5), 1864-1881. https://doi.org/10.3758/s13428-016-08301

Roux, S., \& Bonin, P. (2012). Cascaded processing in written naming: Evidence from the picture-picture interference paradigm. Language and Cognitive Processes, 27(5), 734-769.

https://doi.org/10.1080/01690965.2011.58 0162

Scaltritti, M., Pinet, S., Longcamp, M., \& Alario, F.-X. (2017). On the functional relationship between language and motor processing in typewriting: An EEG study. Language, Cognition and Neuroscience, 32(9), 10861101.

https://doi.org/10.1080/23273798.2017.12 83427

Schnur, T. T. (2014). The persistence of cumulative semantic interference during naming. Journal of Memory and Language, 75, 27-44. https://doi.org/10.1016/j.jml.2014.04.006

Snyder, K. M., Logan, G. D., \& Yamaguchi, M. (2015). Watch what you type: The role of visual feedback from the screen and hands in skilled typewriting. Attention, Perception, \& Psychophysics, 77(1), 282-292. https://doi.org/10.3758/s13414-014-07566

Speed, L. J., Wnuk, E., \& Majid, A. (2018). Studying psycholinguistics out of the lab. In Research methods in psycholinguistics and the neurobiology of language: a practical guide (pp. 190-207). John Wiley \& Sons, Inc.

Stark, K. (2021a). Stringmatch_typed_naming. GitHub Repository.

https://github.com/kirstenstark/stringmatch typed_naming

Stark, K. (2021b). Typing_RTs_JS. GitHub Repository.

https://github.com/kirstenstark/typing_RTs JS

Starreveld, P. A., \& La Heij, W. (2017). Pictureword interference is a Stroop effect: A theoretical analysis and new empirical findings. Psychonomic Bulletin and Review, 24, 721-733. https://doi.org/10.3758/s13423-016-11676 
Torrance, M., Nottbusch, G., Alves, R. A., Arfé, B., Chanquoy, L., Chukharev-Hudilainen, E., Dimakos, I., Fidalgo, R., Hyönä, J., Jóhannesson, Ó. I., Madjarov, G., Pauly, D. N., Uppstad, P. H., van Waes, L., Vernon, M., \& Wengelin, A. (2018). Timed written picture naming in 14 European languages. Behavior Research Methods, 50(2), 744-758.

https://doi.org/10.3758/s13428-017-0902$x$

Van Casteren, M., \& Davis, M. H. (2006). Mix, a program for pseudorandomization. Behavior Research Methods, 38(4), 584589. https://doi.org/10.3758/BF03193889

van der Loo, M. P. J. (2014). The stringdist package for approximate string matching. The $R$ Journal, 16, 1-86.
https://doi.org/10.32614/RJ-2014-011

van Scherpenberg, C., Just, A., \& Hauber, R. (2020). Check voice onset times from chronset with Praat script.

https://osf.io/fmwqb/

Vogt, A., Hauber, R., Kuhlen, A. K., \& Abdel Rahman, R. (2021). Internet based language production research with overt articulation: Proof of concept, challenges, and practical advice. PsyArXiv, 1-35. https://doi.org/10.31234/osf.io/cyvwf

Zhang, Q., \& Damian, M. F. (2010). Impact of phonology on the generation of handwritten responses: Evidence from picture-word interference tasks. Memory \& Cognition, 38(4), 519-528.

https://doi.org/10.3758/MC.38.4.519 
Appendix A: List of Stimuli

\section{Table A1}

Experimental Stimuli (English Translations in Brackets) and Acceptable Synonyms Ordered Alphabetically by Semantic Subcategories

\begin{tabular}{|c|c|c|c|}
\hline Items & Acceptable alternatives & Items & $\begin{array}{l}\text { Acceptable } \\
\text { alternatives }\end{array}$ \\
\hline Birds & & Farming tools & \\
\hline Ente (duck) & & Axt (axe) & Beil \\
\hline Eule (owl) & Uhu & Besen (broom) & Strohbesen \\
\hline Schwan (swan) & & Säge (saw) & Handsäge \\
\hline Strauss (ostrich) & Pfau, Strauch & Schaufel (shovel) & Spaten, Schippe \\
\hline Taube (pidgeon) & & Sense (scythe) & Sichel \\
\hline Body parts & & Flowers & \\
\hline Arm (arm) & & $\begin{array}{l}\text { Löwenzahn } \\
\text { (dandelion) }\end{array}$ & \\
\hline Bein (leg) & & Orchidee (orchid) & \\
\hline Fuss (foot) & & Rose (rose) & \\
\hline Hand (hand) & & $\begin{array}{l}\text { Sonnenblume } \\
\text { (sunflower) }\end{array}$ & \\
\hline Ohr (earring) & & Tulpe (tulip) & \\
\hline Buildings & & Fruits & \\
\hline Burg (fortress) & Schloss & Apfel (apple) & \\
\hline Hochhaus (skyscraper) & Wolkenkratzer & Banane (banana) & \\
\hline Kirche (church) & & Birne (pear) & \\
\hline Schloss (castle) & Palast, Burg & Kirsche (cherry) & \\
\hline Tempel (temple) & $\begin{array}{l}\text { Pantheon, Ruine, } \\
\text { Akropolis }\end{array}$ & Trauben (grapes) & Weintrauben \\
\hline Carpenter's Tools & & Hoofed animals & \\
\hline Bohrmaschine (drill) & Bohrer, Akkuschrauber & Kamel (camel) & \\
\hline Feile (rasp) & Reibe, Spachtel, Hobel & Kuh (cow) & \\
\hline Hammer (hammer) & & Pferd (horse) & \\
\hline $\begin{array}{l}\text { Schraubenzieher } \\
\text { (screwdriver) }\end{array}$ & $\begin{array}{l}\text { Schraubenschlüssel, } \\
\text { Schraubendreher }\end{array}$ & Reh (dear) & \\
\hline Zange (pliers) & & Schaf (sheep) & Lamm \\
\hline Cooking equipment & & Insects & \\
\hline Gabel (fork) & & Ameise (ant) & \\
\hline Kelle (ladle) & Suppenkelle, Rührkelle & Biene (bee) & Bienchen \\
\hline Löffel (spoon) & & Fliege (house fly) & Mücke \\
\hline Messer (knife) & & $\begin{array}{l}\text { Marienkäfer } \\
\text { (ladybird) }\end{array}$ & Käfer \\
\hline Schneebesen (whisk) & Quirl, Rührbesen, Mixer & Spinne (spider) & \\
\hline Drinking vessels & & Instruments & \\
\hline Becher (plastic cup) & $\begin{array}{l}\text { Knobelbecher, } \\
\text { Pappbecher }\end{array}$ & Geige (violin) & Violine \\
\hline Flasche (bottle) & $\begin{array}{l}\text { Glasflasche, } \\
\text { Wasserflasche }\end{array}$ & Gitarre (guitar) & \\
\hline Glas (glass) & Becher & Harfe (harp) & \\
\hline Kanne (teapot) & $\begin{array}{l}\text { Teekanne, Teekessel, } \\
\text { Kaffeekanne }\end{array}$ & Klavier (piano) & Piano \\
\hline Tasse (tea cup) & Teetasse, Becher & Schlagzeug (drum & \\
\hline
\end{tabular}




\begin{tabular}{|c|c|c|c|}
\hline Items & Acceptable alternatives & Items & Acceptable alternatives \\
\hline Jackets & & Seating furniture & \\
\hline Arztkittel (lab coat) & $\begin{array}{l}\text { Chemiekittel, Kittel, } \\
\text { Laborkittel }\end{array}$ & Bank (bank) & \\
\hline $\begin{array}{l}\text { Daunenweste (down } \\
\text { vest) }\end{array}$ & Weste & Couch (couch) & Sofa, Ledercouch \\
\hline Kapuzenpulli (sweater) & $\begin{array}{l}\text { Pulli, Pullover, Hoodie, } \\
\text { Kapuzenpullover }\end{array}$ & Hocker (stool) & Schemel \\
\hline Pelzmantel (fur coat) & Mantel, Pelz, Fellmantel & Sessel (armchair) & \\
\hline Sakko (sport coat) & Anzug, Jackett & Stuhl (chair) & \\
\hline Fish & & Storage & \\
\hline Aal (eel) & & $\begin{array}{l}\text { Kleiderschrank } \\
\text { (wardrobe) }\end{array}$ & Schrank \\
\hline Delfin (dolfin) & & Regal (cupboard) & \\
\hline Goldfisch (goldfish) & Fisch & Safe (safe) & Tresor \\
\hline Hai (shark) & Haifisch & Schachtel (box) & $\begin{array}{l}\text { Kiste, Box, Kasten, } \\
\text { Schachtel, Karton, } \\
\text { Schuhbox }\end{array}$ \\
\hline Rochen (ray) & Mantarochen, Manta & $\begin{array}{l}\text { Schublade } \\
\text { (drawer) }\end{array}$ & Schubkaste \\
\hline Jewelry & & Street vehicles & \\
\hline Armband (bracelet) & $\begin{array}{l}\text { Armband, Armkette, } \\
\text { Armreif }\end{array}$ & Auto (car) & SUV, Mercedes \\
\hline Brosche (brooch) & $\begin{array}{l}\text { Schmuck, Amulett, } \\
\text { Diadem, Juwelen, } \\
\text { Schmuck, Haarspange, }\end{array}$ & Bus (bus) & \\
\hline Kette (necklace) & $\begin{array}{l}\text { Collier, Halskette, } \\
\text { Perlenkette, Halsband }\end{array}$ & Kutsche (carriage) & \\
\hline Ohrring (earring) & Ohranhänger & Lkw (truck) & $\begin{array}{l}\text { Lastkraftwagen, Laster, } \\
\text { Lastwagen, Transporter }\end{array}$ \\
\hline Ring (ring) & Goldring, Ehering & Motorrad (motorcycl & \\
\hline Kitchen furniture & & Sweets & \\
\hline $\begin{array}{l}\text { Geschirrspüler } \\
\text { (dishwasher) }\end{array}$ & $\begin{array}{l}\text { Geschirrspülmaschine, } \\
\text { Spülmaschine, } \\
\text { Geschirrwaschmaschine, } \\
\text { Spüler }\end{array}$ & Bonbon (candy) & \\
\hline Herd (stove) & $\begin{array}{l}\text { Kochfeld, Herdplatte, } \\
\text { Ofen, Ofenplatte, }\end{array}$ & Eis (ice cream) & Schokoladeneis, Eiscreme \\
\hline $\begin{array}{l}\text { Kaffeemaschine (coffee } \\
\text { machine) }\end{array}$ & Kaffeekocher & Kekse (biscuit) & $\begin{array}{l}\text { Keks, Schokoladenkeks, } \\
\text { Cookies }\end{array}$ \\
\hline Kühlschrank (fridge) & Gefrierschrank & Kuchen (cake) & Torte \\
\hline Mikrowelle (microwave) & & Schokolade (chocola & ate) \\
\hline Office tools & & Vegetables & \\
\hline Bleistift (pencil) & Stift & Brokkoli (broccoli) & \\
\hline Klammer (paper-clip) & $\begin{array}{l}\text { Büroklammer, Clip, } \\
\text { Briefklammer }\end{array}$ & Gurke (cucumber) & Salatgurke \\
\hline Lineal (ruler) & Zollstock & Karotte (carrot) & Möhre \\
\hline Radiergummi (rubber) & Radierer & Kartoffel (potato) & \\
\hline Schere (scissors) & & $\begin{array}{l}\text { Paprika (bell } \\
\text { pepper) }\end{array}$ & Grüne Paprika \\
\hline Predatory animals & & Water vehicles & \\
\hline Bär (bear) & Braunbär & Gondel (gondola) & Gondola, Gondelier, Boot \\
\hline Leopard (leopard) & Gepard, Jaguar, Puma & Kanu (canoe) & Boot \\
\hline Löwe (lion) & & $\begin{array}{l}\text { Segelschiff (sailing } \\
\text { boat) }\end{array}$ & $\begin{array}{l}\text { Modellschiff, Segelboot, } \\
\text { Schiff, Boot }\end{array}$ \\
\hline Panther (panther) & Puma, Jaguar, Gepard & $\begin{array}{l}\text { U-Boot } \\
\text { (submarine) }\end{array}$ & $\begin{array}{l}\text { Unterseeboot, Militärschiff, } \\
\text { Boot }\end{array}$ \\
\hline Tiger (tiger) & & Yacht (yacht) & Schiff, Boot \\
\hline
\end{tabular}


Appendix B: Experiments 1 and 2-RTs and Error Rates by Participants and Categories Figure B1

Normalized Mean Naming Latencies (RTs) in Milliseconds as a Function of Ordinal Position for Each (A) Participant and (B) Category in Experiment 1
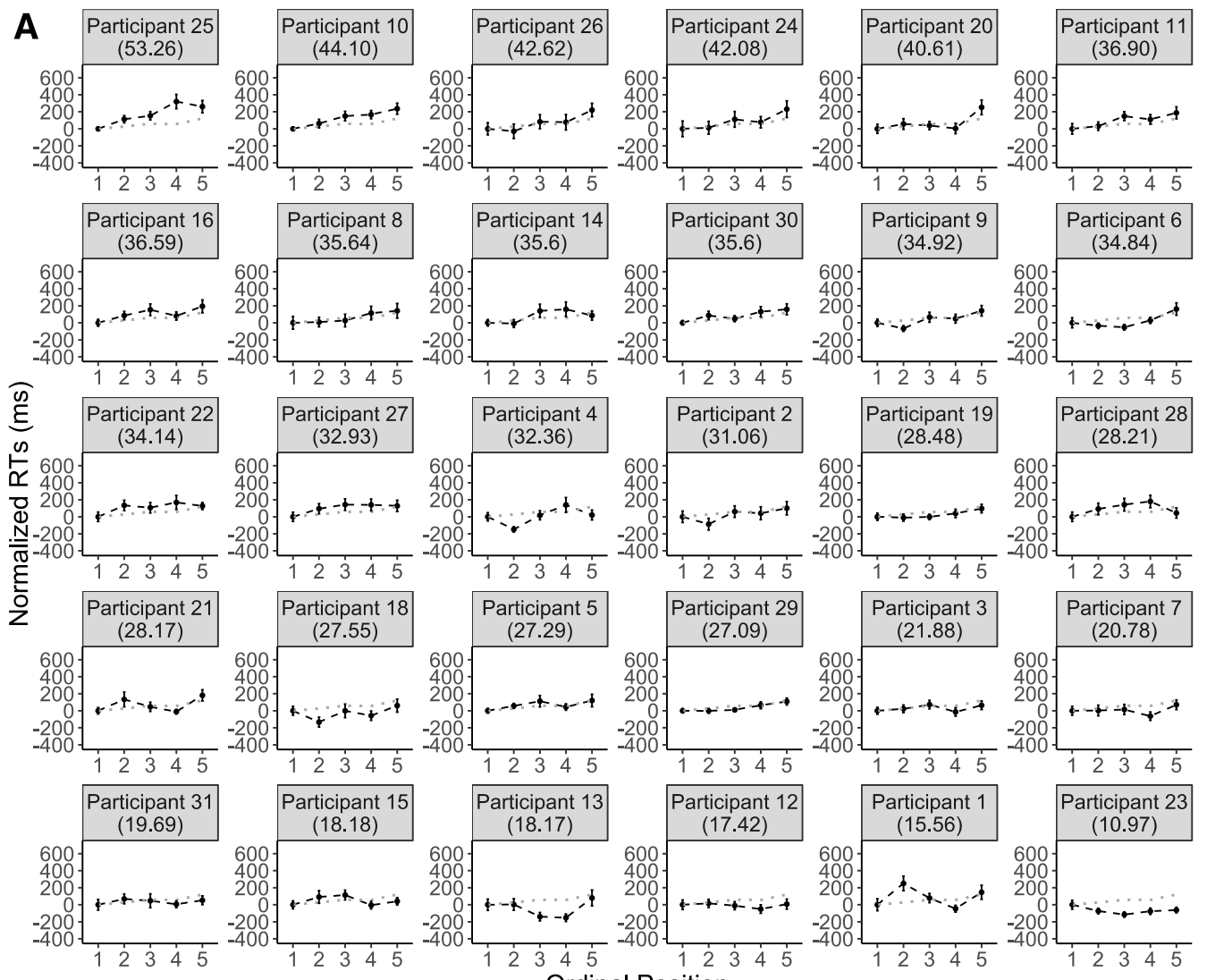

- Participant mean

Mean across participants
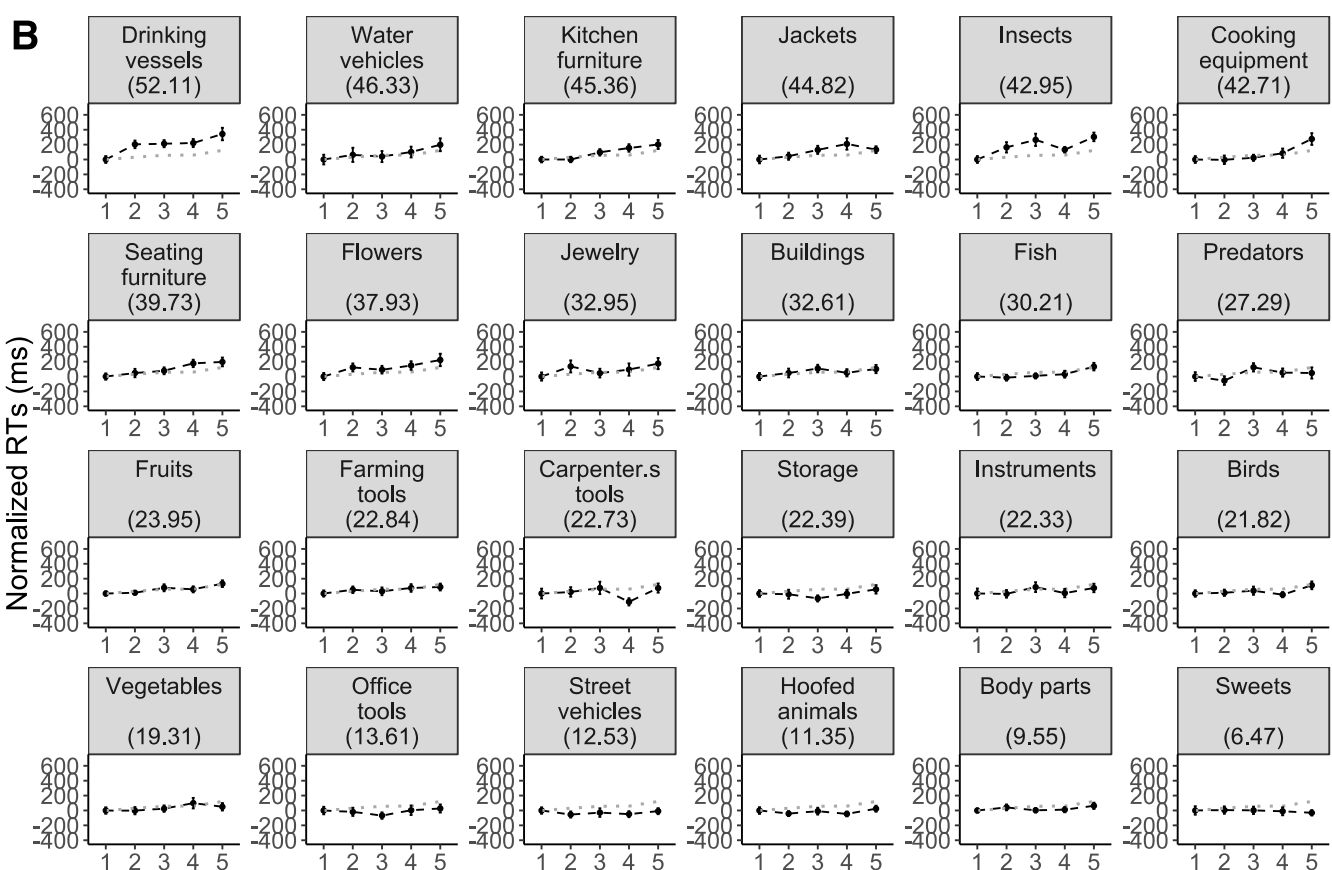

$123 \quad 45$

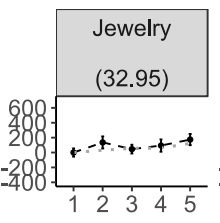

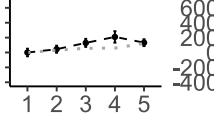

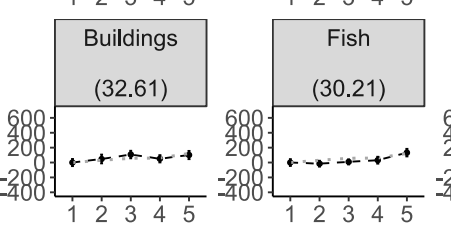
(37.93)
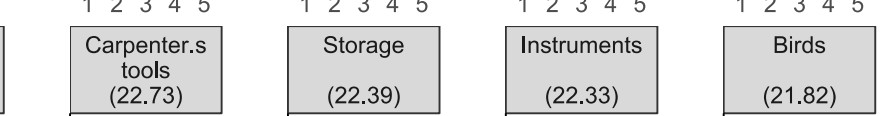

(22.84)

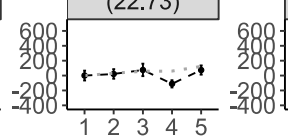

(22.39)

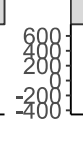

(1.82)
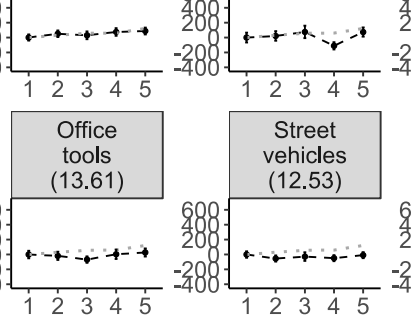

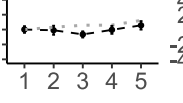
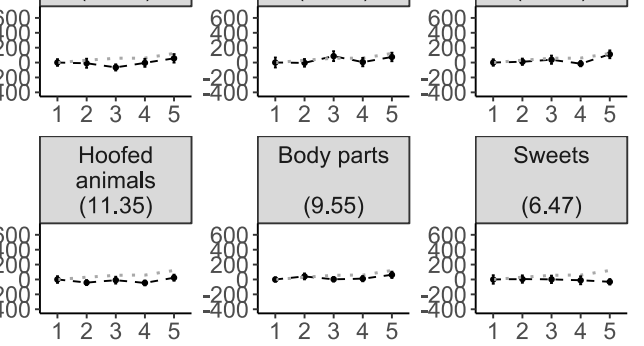


\section{WEB-BASED SPOKEN AND TYPED LANGUAGE PRODUCTION EXPERIMENTS}

Note. Mean normalized reaction times in milliseconds per ordinal position. Subplots show the reaction times for each participant (category) separately, ordered by the size of their CSI effect, i.e., the average increase per ordinal position as estimated by the GLMM (see results section) shown in grey boxes above each graph. Mean reaction times were calculated across semantic categories (participants). The RTs were normalized for each participant (category) by subtracting the mean of the first ordinal position from the respective means of the other ordinal positions. The grey dotted line shows the mean RT per ordinal position across participants and categories. Error bars show standard errors of the mean. Values were adjusted for within-participant designs using the method suggested by Morey (Morey, 2008) as implemented in the summarySEwithin() function from the R package Rmisc (Hope, 2013). 


\section{WEB-BASED SPOKEN AND TYPED LANGUAGE PRODUCTION EXPERIMENTS}

\section{Figure B2}

Normalized Error Rate in Percent as a Function of Ordinal Position for Each (A) Participant and $(B)$ Category in Experiment 1
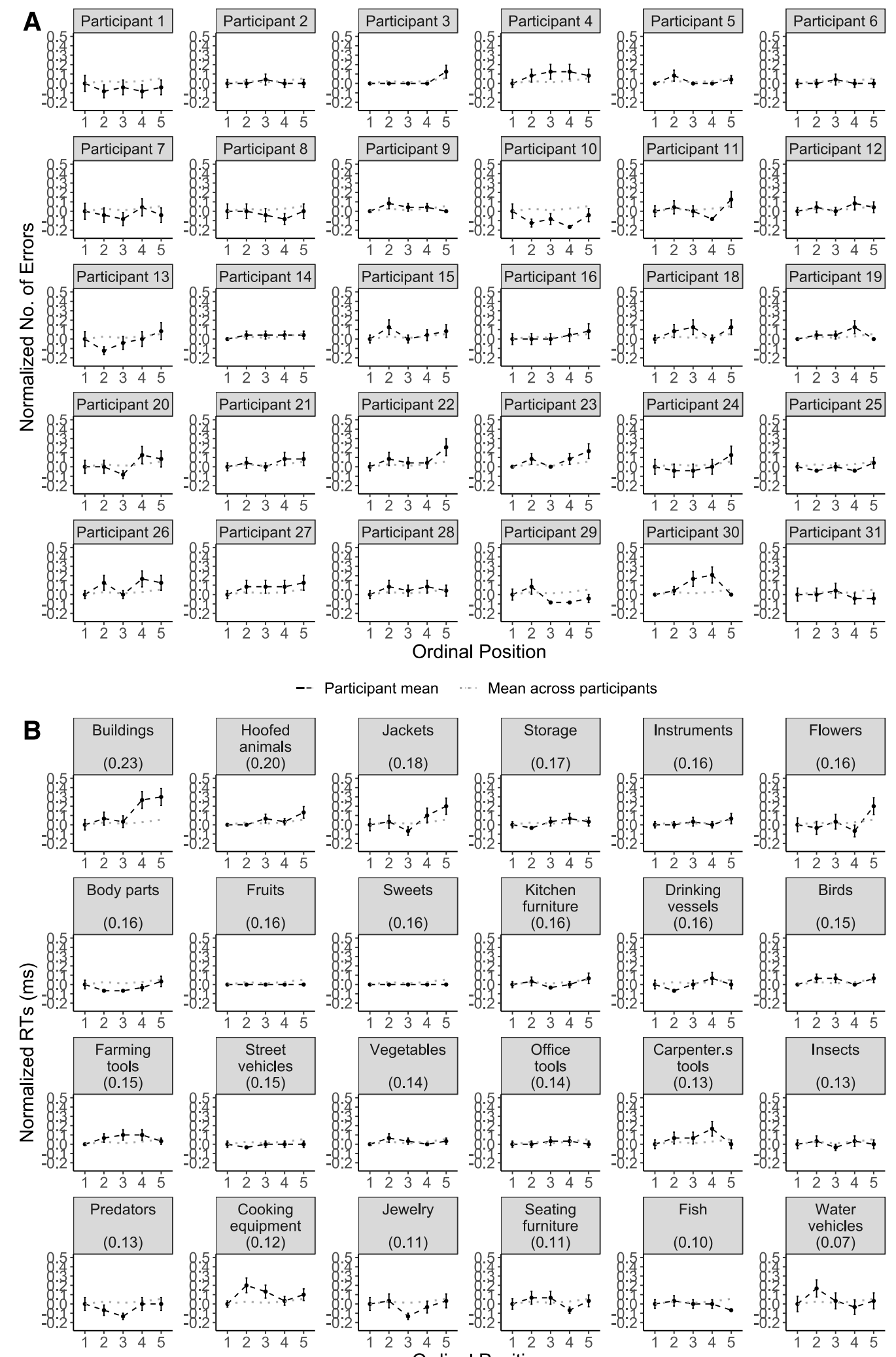

Participant mean

Mean across participants
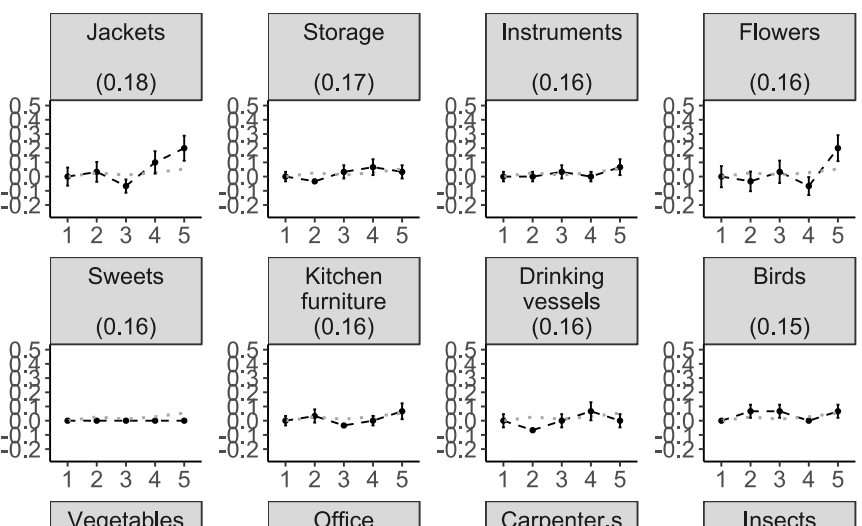

$(0.15$
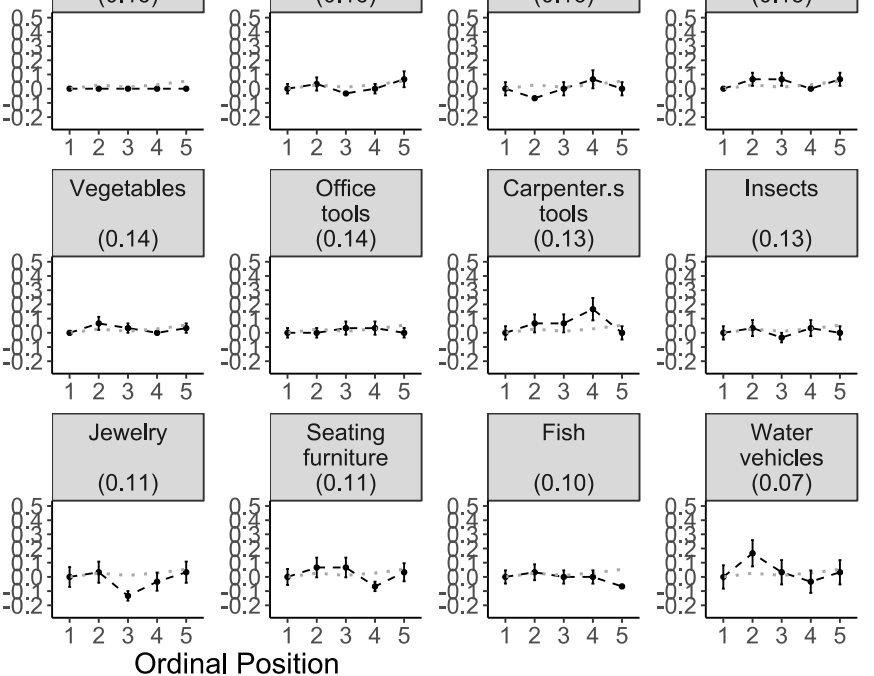

Mean across categories 
Note. Mean normalized error rates per ordinal position. Subplots show error rates for each participant (category) separately. Mean error rates were calculated across semantic categories (participants). The error rates were normalized for each participant (category) by subtracting the mean of the first ordinal position from the respective means of the other ordinal positions. The grey dotted line shows the mean error rate per ordinal position across participants and categories. Error bars show standard errors of the mean. Values were adjusted for within-participant designs using the method suggested by Morey (Morey, 2008) as implemented in the summarySEwithin() function from the R package Rmisc (Hope, 2013). 


\section{WEB-BASED SPOKEN AND TYPED LANGUAGE PRODUCTION EXPERIMENTS}

\section{Figure B3}

Normalized Mean Typing Latencies (RTs) in Milliseconds as a Function of Ordinal Position for Each (A) Participant and (B) Category in Experiment 2
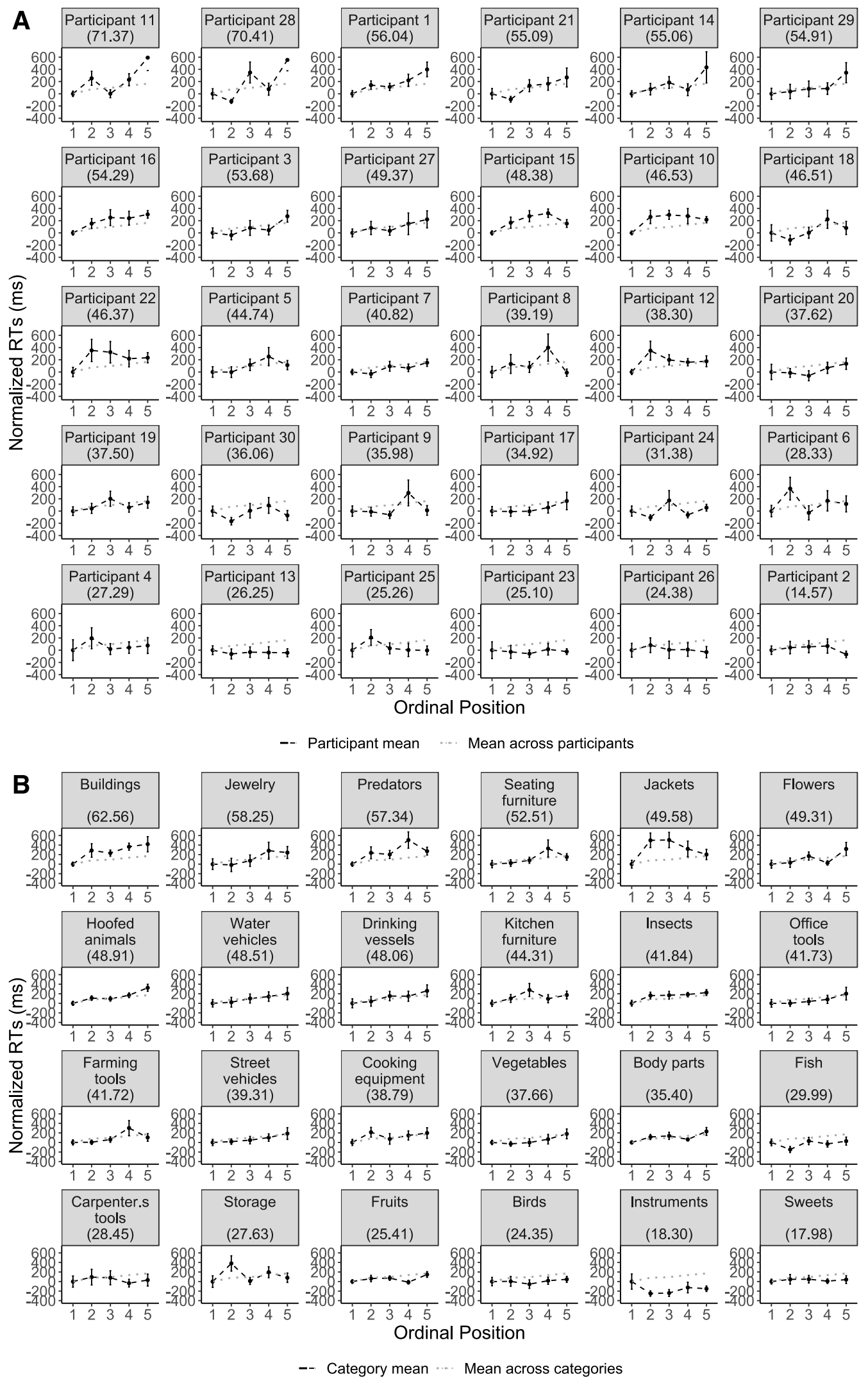


\section{WEB-BASED SPOKEN AND TYPED LANGUAGE PRODUCTION EXPERIMENTS}

Note. Mean normalized reaction times in milliseconds per ordinal position. Subplots show the reaction times for each participant (category) separately, ordered by the size of their CSI effect, i.e., the average increase per ordinal position as estimated by the GLMM (see results section) shown in grey boxes above each graph. Mean reaction times were calculated across semantic categories (participants). The RTs were normalized for each participant (category) by subtracting the mean of the first ordinal position from the respective means of the other ordinal positions. The grey dotted line shows the mean RT per ordinal position across participants and categories. Error bars show standard errors of the mean. Values were adjusted for within-participant designs using the method suggested by Morey (Morey, 2008) as implemented in the summarySEwithin() function from the R package Rmisc (Hope, 2013). 


\section{WEB-BASED SPOKEN AND TYPED LANGUAGE PRODUCTION EXPERIMENTS}

\section{Figure B4}

Normalized Error Rate in Percent as a Function of Ordinal Position for Each (A) Participant and (B) Category in Experiment 2
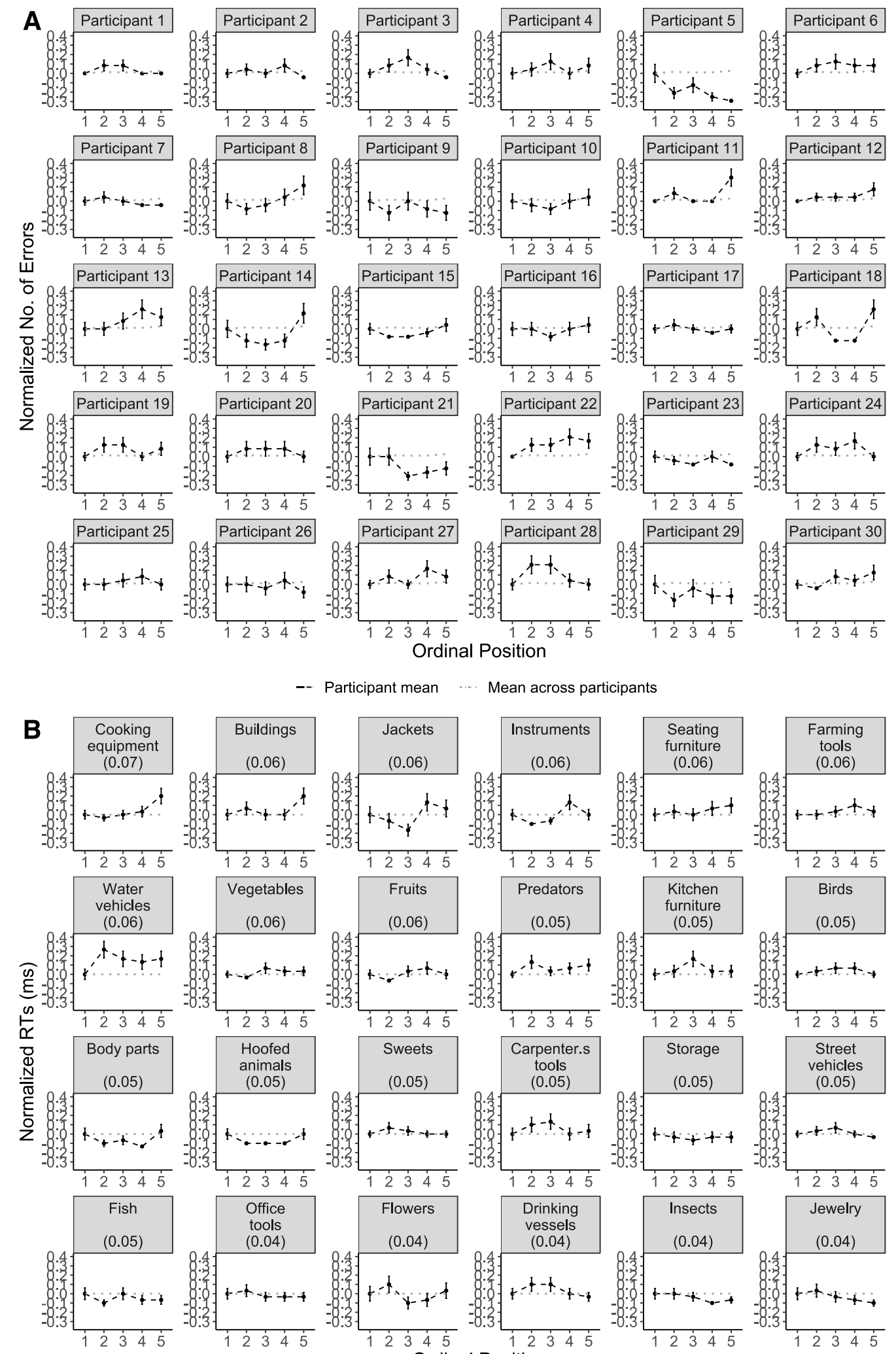

Participant mean

Mean across participants
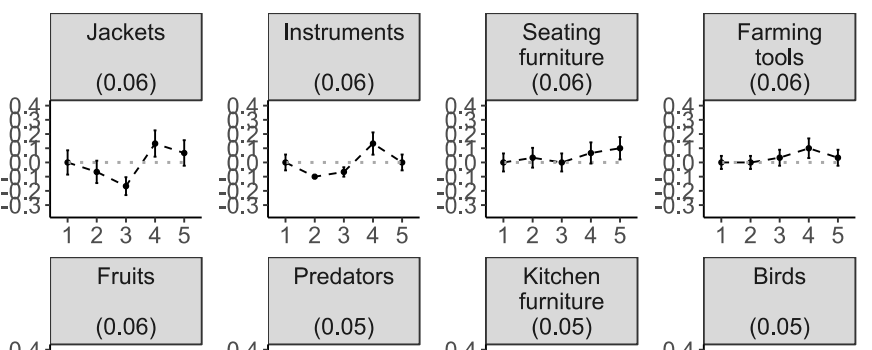

3.

$+-\infty-t-t-1$

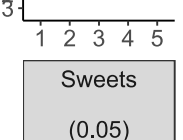

$8:$

$-4-t-1$
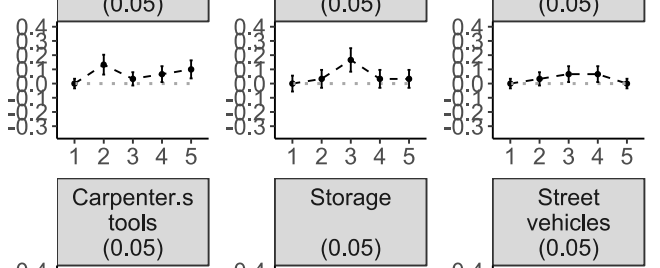

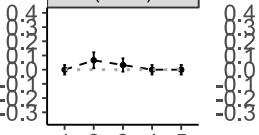
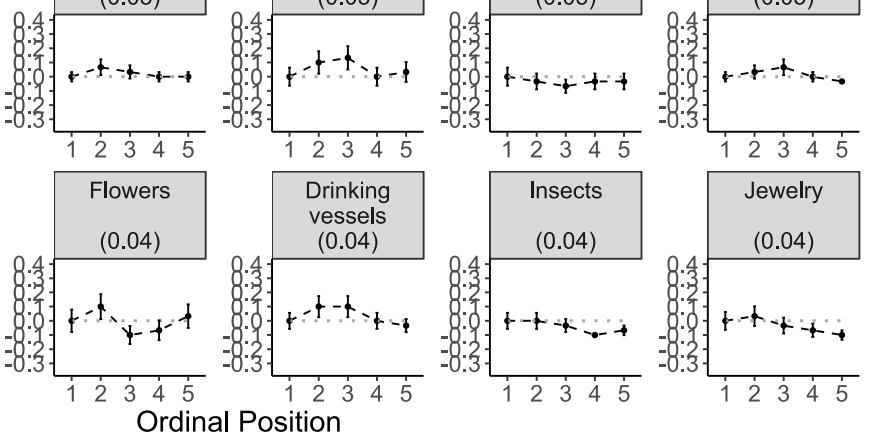

-- Category mean

Mean across categories 
Note. Mean normalized error rates per ordinal position. Subplots show error rates for each participant (category) separately. Mean error rates were calculated across semantic categories (participants). The error rates were normalized for each participant (category) by subtracting the mean of the first ordinal position from the respective means of the other ordinal positions. The grey dotted line shows the mean error rate per ordinal position across participants and categories. Error bars show standard errors of the mean. Values were adjusted for within-participant designs using the method suggested by Morey (Morey, 2008) as implemented in the summarySEwithin() function from the R package Rmisc (Hope, 2013). 


\section{Appendix C: Experiment 2-Comparison of Further Automated String Matching Procedures}

To date, there are a wide range of string matching metrics available, each with specific characteristics and applications. In our main analyses, we chose to use the Jaro distance (cut-off: $d_{\mathrm{Jaro}} \geq .3$; Jaro, 1989,1995$)$ because this metric was tailored specifically to short string inputs. Here, we compare the manual and automated classifications with further string matching metrics, the Jaro-Winkler distance $(p=0.1$; cut-off: $d \geq .3)$, the Levenshtein distance (equal weights of 1 each; cut-off: $d \geq 3$ ), the optimal string alignment (also called restricted Damerau-Levenshtein distance; equal weights of 1 each; cut-off: $d \geq 4$ ), and the Jaccard bi-gram distance ( $q=2$; cut-off: $d \geq 0.8$ ). For all metrics, we used our custom preprocessing functions (see description in the methods section of this manuscript; https://github.com/kirstenstark/stringmatch typed naming), and the technical implementations from the stringdist package (version 0.9.6.3; van der Loo, 2014). For the exact formula applied, we may refer to van der Loo (van der Loo, 2014).

As shown in Table C1, all metrics yielded very similar classifications that were close to perfectly correlated with our intuitive, manual classification. The numerically highest correlation was found between the manual classification and the Levenshtein distance and the optimal string alignment metric. Those were also somewhat more conservative, because, in comparison to the other metrics, they classified slightly less words as correct that intuitively were classified as incorrect and more words as incorrect that intuitively were classified as correct. 
WEB-BASED SPOKEN AND TYPED LANGUAGE PRODUCTION EXPERIMENTS

Table C1

Comparison of Different Automated String Matching Metrics

\begin{tabular}{|c|c|c|c|c|c|c|c|c|}
\hline \multirow[t]{2}{*}{ Metric } & \multirow{2}{*}{$\begin{array}{c}r \\
\text { (manual) }\end{array}$} & \multicolumn{3}{|c|}{ "New correct" words } & \multicolumn{4}{|c|}{ "New incorrect" words } \\
\hline & & $\begin{array}{l}\text { Partial } \\
\text { name }\end{array}$ & $\begin{array}{c}\text { Orthogra } \\
\text { ph.simila } \\
\text { rity }\end{array}$ & $\begin{array}{l}\text { Loose } \\
\text { ly } \\
\text { relate } \\
\text { d }\end{array}$ & $\begin{array}{c}1^{\text {st }} \text { letter } \\
\text { backspa } \\
\text { ce }\end{array}$ & $\begin{array}{c}\text { Phonol } \\
\text { og. } \\
\text { similarit } \\
\text { y (1 } 1^{\text {st }} \\
\text { letter })\end{array}$ & $\begin{array}{c}\text { Distanc } \\
\text { e- } \\
\text { based }\end{array}$ & $\begin{array}{c}\text { Othe } \\
r\end{array}$ \\
\hline Jaro & .969 & 5 & 2 & 1 & 13 & 6 & 1 & 1 \\
\hline $\begin{array}{l}\text { Jaro- } \\
\text { Winkler }\end{array}$ & .962 & 5 & 2 & 6 & 14 & 6 & 1 & - \\
\hline $\begin{array}{l}\text { Leven- } \\
\text { shtein }\end{array}$ & .971 & - & - & 1 & 14 & 6 & 6 & - \\
\hline $\begin{array}{l}\text { Optimal } \\
\text { string } \\
\text { alignme } \\
\text { nt }\end{array}$ & .971 & - & 1 & 1 & 14 & 6 & 5 & - \\
\hline $\begin{array}{l}\text { Bi-gram } \\
\text { (Jaccar } \\
\text { d) }\end{array}$ & .963 & 4 & 2 & 1 & 15 & 6 & 4 & 2 \\
\hline
\end{tabular}

Note. $r$ (manual) $=$ Pearson's $r$ correlation of the manual classification and the respective string matching metric; "New correct" words = Number of typed words manually classified as incorrect, but as correct with the respective metric, leading to lower trial exclusion; "New incorrect" words = Number of typed words manually classified as correct, but as incorrect with the respective metric, leading to higher trial exclusion; Partial name = when participants typed only parts of the picture name (e.g., GESCHIRR [engl. dish] instead of GESCHIRRSPÜLER [engl. dishwasher]); Orthograph. similarity = when participants typed orthographically similar words (e.g., KESSEL [engl. kettle] instead of KELLE [engl. ladle]); Loosely related = when participants typed words that were semantically related to the target word, but no accepted alternative (e.g., SCHEMEL [engl. taboret] instead of STUHL [engl. chair]); $1^{\text {st }}$ letter backspace $=$ when participants backspace-corrected an accepted alternative, changing the first character of the word entry (e.g.,

BURBackspaceBackspaceBackspaceBackspaceSCHLOSS [engl. castl(e)...fortress]); Phonolog. similarity $\left(1^{\text {st }}\right.$ letter $)=$ when participants misspelled the beginning of a word with a phonologically similar phoneme (e.g., PFEILE instead of FEILE [engl. similar to wrasp instead of rasp]), Distancebased $=$ when the computed distance was higher than the respective cut-off; Other = classification differences that were difficult to classify. 
Appendix D: Experiment 2-Analyses of Manually Classified Typewritten Answers

Here, we report the results of the preregistered RT data analysis of the manually/halfautomatically classified data from experiment 2 . For a description of the procedures, we may refer to the methods section of this manuscript.

The mean reaction times, i.e., the latencies between picture onset and first keystroke show a linear increase with ordinal position (Table D1). The GLMM confirmed this linear trend: As with the automatically pre-processed data, RTs increased significantly with an average of 42 ms per additional member of each category (Table D2).

Table D1

Typing Latencies in Milliseconds (RTs) and Erroneous Trials for Each Ordinal Position

\begin{tabular}{lccccc}
\hline \multirow{2}{*}{$\begin{array}{c}\text { Typing latencies } \\
\text { (RTs) }\end{array}$} & \multicolumn{5}{c}{ Ordinal position } \\
\cline { 2 - 6 } & 1 & 2 & 3 & 4 & 5 \\
\hline$M$ & 1151.61 & 1224.81 & 1247.35 & 1285.51 & 1317.46 \\
SEM & 17.43 & 21.77 & 20.67 & 23.53 & 22.44 \\
\hline Erroneous trials & 73 & 84 & 79 & 83 & 94 \\
\hline
\end{tabular}

Note. $M=$ mean; $S E M=$ standard error of the mean; Erroneous trials = Number of trials per ordinal position that were excluded due to errors (technical or answer-based). SEMs were adjusted for withinparticipant designs using the method suggested by Morey (Morey, 2008) as implemented in the summarySEwithin() function from the R package Rmisc (Hope, 2013).

\section{Table D2}

Generalized Linear Mixed Model (GLMM) With Gamma Identity Link Function Predicting Typing Latencies (RTs) by Ordinal Position

\begin{tabular}{|c|c|c|c|c|}
\hline Effect & Estimate $\quad S E$ & $95 \% \mathrm{Cl}$ & $t$-value & $p$ \\
\hline
\end{tabular}

\section{Model: RT ordinal position + (ordinal position | subject) + (ordinal position | category)}

Fixed effects

$\begin{array}{lcccccc}\text { Intercept } & 1296.05 & 12.64 & 1272.01 & 1320.09 & 105.68 & <0.001 \\ \text { Ordinal } & 42.32 & 7.21 & 28.18 & 56.46 & 5.87 & <0.001 \\ \text { position } & & & & & & \end{array}$

Note. Number of participants $=30$; number of categories $=24$; total $N=3187 ; S E=$ standard error; $\mathrm{Cl}=$ confidence interval around the estimate; $L L=$ lower limit; $U L=$ upper limit. 